\title{
Systematic review of the receptor tyrosine kinase superfamily in neuroblastoma pathophysiology
}

\author{
Esteban Javier Rozen ${ }^{1}$ D . Jason Matthew Shohet $^{2}$
}

Received: 26 August 2021 / Accepted: 14 October 2021 / Published online: 30 October 2021

(c) The Author(s) 2021

\begin{abstract}
Background Neuroblastoma is a devastating disease accounting for $15 \%$ of all childhood cancer deaths. Yet, our understanding of key molecular drivers such as receptor tyrosine kinases (RTKs) in this pathology remains poorly clarified. Here, we provide a systematic analysis of the RTK superfamily in the context of neuroblastoma pathogenesis.

Methods Statistical correlations for all RTK family members' expression to neuroblastoma patient survival across 10 independent patient cohorts were annotated, synthesized, and ranked using the R2: Genomics Analysis and Visualization Platform. Gene expression of selected members across different cancer cell lines was further analyzed in the Cancer Cell Line Encyclopedia, part of the Cancer Dependency Map portal (depmap portal (http://depmap.org)). Finally, we provide a detailed literature review for highly ranked candidates.

Results Our analysis defined two subsets of RTKs showing robust associations with either better or worse survival, constituting potential novel players in neuroblastoma pathophysiology, diagnosis, and therapy. We review the available literature regarding the oncogenic functions of these RTKs, their roles in neuroblastoma pathophysiology, and potential utility as therapeutic targets.

Conclusions Our systematic analysis and review of the RTK superfamily in neuroblastoma pathogenesis provides a new resource to guide the research community towards focused efforts investigating signaling pathways that contribute to neuroblastoma tumor establishment, growth, and/or aggressiveness and targeting these druggable molecules in novel therapeutic strategies.
\end{abstract}

Keywords RTK $\cdot$ Kinase inhibitor $\cdot$ Neuroblastoma $\cdot$ RET $\cdot$ DDR2

\section{Introduction}

\subsection{The receptor tyrosine kinase superfamily}

The human genome comprises 58 known receptor tyrosine kinase (RTK) genes, further classified into 20 families. Members of this superfamily are involved in virtually every

Esteban Javier Rozen

esteban.rozen@umassmed.edu

$\triangle$ Jason Matthew Shohet jason.shohet@umassmed.edu

1 Department of Pediatrics, UMass Chan Medical School, Lazare Research Building LRB603, 364 Plantation Street, Worcester, MA 01605, USA

2 Division of Hematology/Oncology, Department of Pediatrics, UMass Chan Medical School, Lazare Research Building LRB603, 364 Plantation Street, Worcester, MA 01605, USA aspect of cellular and organismal life, including cell survival/apoptosis, cell growth and proliferation, metabolism, migration, cell cycle progression, and differentiation $[1,2]$. All RTKs share a similar domain organization, composed of a specific extracellular region, harboring the ligand-binding domain, a single transmembrane helix, and an intracellular motif containing the tyrosine kinase (TK) domain. Most also contain additional juxta-membrane and C-terminal regulatory/effector motifs (Fig. 1A). RTKs are generally activated by receptor-specific ligands, such as soluble ligands/growth factors (GF), adjacent cell surface-bound ligands (ephrins), or extracellular matrix (EM) components (e.g., collagen for DDR1/2), which interact with the ligand binding domain of their cognate RTKs. This leads to dimerization or oligomerization, and activation of the kinase domain, with subsequent trans-autophosphorylation on specific tyrosine residues within the RTK's C-terminal tail [3]. These phosphorylated tyrosine residues in turn act as docking sites for 
Fig. 1 RTK-dependent signaling pathways. a RTK signaling. Ligands of different nature bind to their cognate RTK triggering a battery of classical and context-dependent signal transduction cascades to fulfil a wide range of cellular functions (see main text for details). b RYK/ROR in Wnt signaling. RYK, ROR, and a few other RTK members act as receptors for the Wnt family of ligands, leading to both canonical and non-canonical Wnt-signaling and diverse biological outputs (see main text for details). GF, growth factor (or other soluble ligands); DAG, diacylglycerol; $\mathrm{IP}_{3}$, inositol-1,4,5-triphosphate; $\mathrm{PIP}_{2}$, phosphatidyl-inositol4,5-bisphosphate; $\left[\mathrm{Ca}^{2+}\right]_{\mathrm{i}}$, intracellular calcium ion concentration a

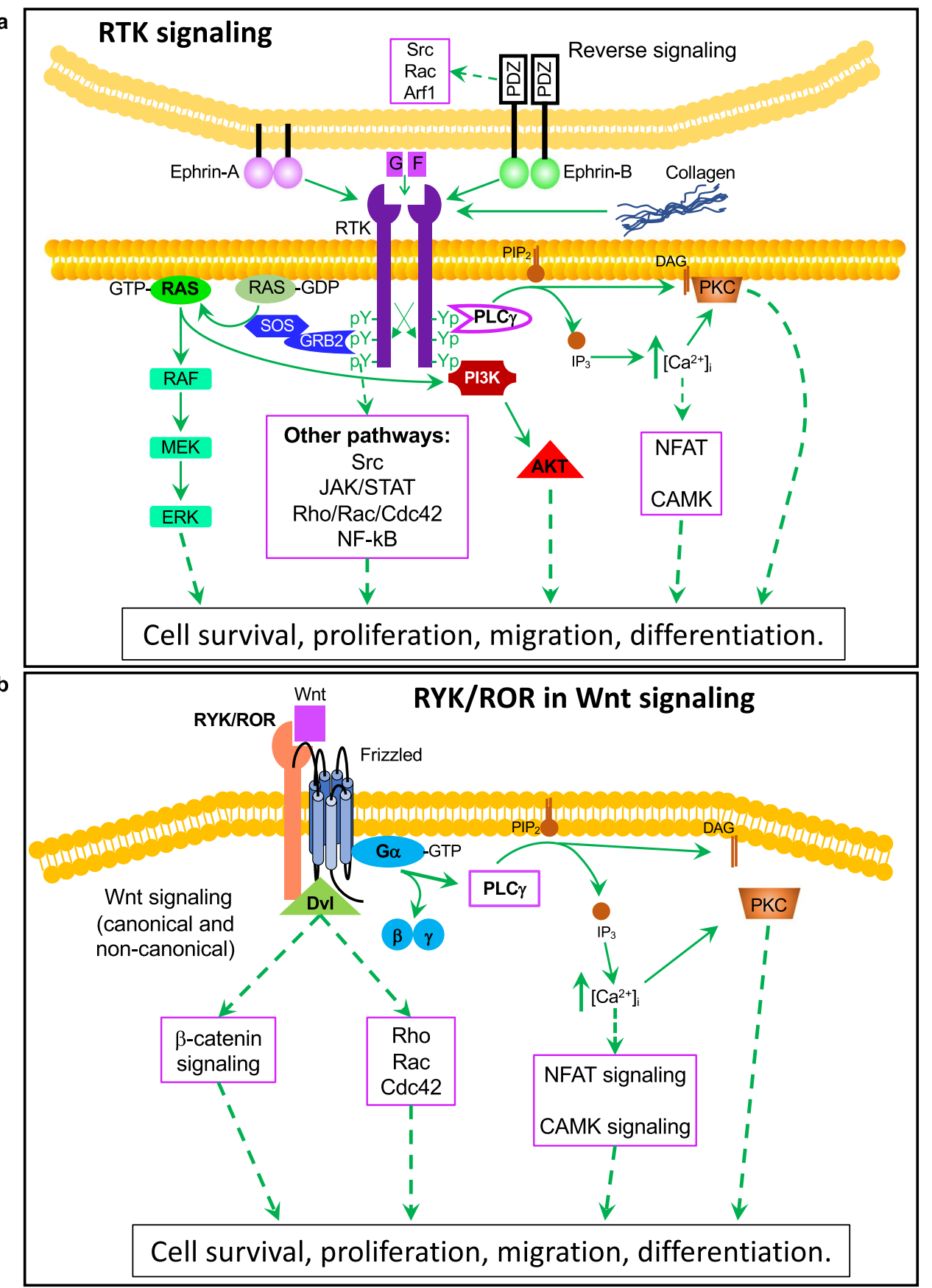

the recruitment and activation of adaptor and effector proteins to propagate and amplify the signals through different transduction cascades. These include the classical PLC $\gamma /$ $\mathrm{Ca}^{2+} / \mathrm{PKC}$, Ras/MAPK, and PI3K/AKT pathways or the more context-specific JAK/STAT, Rho family of GTPases, or Src family of kinases, among others [4, 5] (Fig. 1a). A deviation from this general mechanism of signaling is documented for a subset of RTKs, namely RYK, ROR1/2, PTK7, and MUSK. Except for the later, these RTKs are classified as pseudokinases, as they lack a kinase activity. Instead, this group of RTKs act as co-receptors for WNT family ligands, triggering both canonical and non-canonical WNT-mediated signaling pathways (Fig. 1b; reviewed in [6]). The overall topology of RTKs, their mechanisms of activation, and downstream intracellular signaling components are highly conserved throughout the evolution from nematodes to humans. Therefore, it is not surprising that dysregulation of RTK signaling leads to many human diseases including cancer (reviewed in [4]).

Numerous genomic and cellular studies have revealed many types of context-specific pathogenic alterations in RTK genes including oncogenic mutations and epigenetic 
modifications of EGFR, HER2, and MET, among many others [4]. Such studies have led to the development of novel therapeutic compounds that block or attenuate RTK signaling. Noteworthy, the therapeutic efficacy of RTK inhibitors in oncology is highly dependent on the cell context and the relative contribution of different RTK signaling pathways in the development of a given cancer. In this regard, the critical roles that specific RTKs play in the initiation, metastasis, drug resistance, and relapse in neuroblastoma are just starting to emerge, although very little is yet known for the most part, warranting further efforts to increase our current knowledge on this broad topic.

\subsection{Neuroblastoma}

Neuroblastoma is the most common extracranial malignant tumor in children, accounting for $7 \%$ of all pediatric neoplasms in patients under 15 years and about $13 \%$ of all pediatric cancer deaths. The biological heterogeneity of neuroblastoma results in a variety of clinical presentations. Patients with low- and intermediate-risk neuroblastoma have favorable prognosis and an excellent 5-year survival rate with surgical resection and modest chemotherapy. However, in the case of high-risk metastatic neuroblastoma survival is between 50 and $60 \%$, despite highly genotoxic chemotherapy, radiation, and surgery (reviewed in [7]). Efforts to improve survival and reduce long-term impact of treatment will require novel therapeutics such as innovative application of small molecule RTK inhibitors, epigenetic targeting, and other neuroblastoma context-specific interventions.

While neuroblastoma tumorigenesis is thought to arise from the disrupted development of sympatho-adrenergic precursors of the neural crest, no common genetic or epigenetic alteration has been found to account for most cases of neuroblastoma [8]. Structural genomic changes found in subsets of neuroblastoma, and linked to tumorigenesis and reduced survival, include $M Y C N$ amplification, $A L K$ activating mutations, $1 \mathrm{p} 36$ deletion, or $17 \mathrm{q}$ gain $[9,10]$. The MYCN oncogene plays a major role in neural crest development and neuroblastoma tumorigenesis and defines an aggressive subset of tumors. Amplification of $M Y C N$ (defined as $>10$ copies) is found in about half of all highrisk tumors and confers a particularly poor prognosis. The "anaplastic lymphoma kinase" $(A L K)$ gene belongs to the RTK superfamily. Activating mutations for ALK are found in $6-10 \%$ of spontaneous cases and in almost $50 \%$ cases of familial neuroblastoma (1-2\% of total neuroblastoma cases) [11]. This RTK has also been implicated as an oncogene in lymphomas and lung cancers, where it is typically found as a translocated fusion gene (e.g., $A L K$ $N P M)[12,13]$. Recent studies link $A L K$ to sympathetic neuron development and survival of migratory neural crest cells [14]. This gene is a direct transcriptional target of
MYCN and is an important regulator of stemness, including STAT3-dependent self-renewal $[15,16]$. Recent data from genetically engineered mouse models of neuroblastoma confirm that ALK and MYCN cooperate to promote tumorigenesis [17]. Importantly, potent ALK inhibitors are already in clinical trials for ALK-mutant neuroblastomas.

While some of the roles that ALK and a few other RTK family members play in neuroblastoma initiation, progression, or aggressiveness have been examined, the rationale for such studies has usually been linked to known functions of such genes in other cancer paradigms. This may not necessarily reflect a specific tumorigenic function in the context of neuroblastoma pathogenesis. Despite the functions of several RTKs have been widely studied in the context of neural crest differentiation (reviewed in [18]), a systematic unbiased review on the contribution of the RTK superfamily to neuroblastoma pathogenesis is lacking.

In order to establish a rationale for the systematic analysis of the RTK superfamily in neuroblastoma, we initially annotated, synthesized, and ranked the correlation between overall survival probability and gene expression for all 58 members of the RTK superfamily (sorted by phylogenetic order) across ten independently annotated patient cohorts (Cangelosi, Kocak, SEQC-RPM, SEQC-custom, Primary NRC, Oberthuer, TARGET-Asgharzadeh, Seeger, Maris, and Versteeg) with available patient survival data in the R2: Genomics Analysis and Visualization Platform (http:// r2.amc.nl) [19] (Supplementary Fig. 1; see Fig. 3a for a representative example of the correlation plots from which the adjusted $p$ values were taken).

Re-sorting of the RTK superfamily gene list by score (Fig. 2) clearly defined two subsets of RTKs showing significant associations to either worse (Fig. 2 top subset) or better (Fig. 2 bottom subset) prognosis across at least 5 independent cohorts, thus implying a potential role for each of these RTKs as critical regulators of neuroblastoma pathogenesis. Among the RTKs showing a robust positive correlation (higher expression $=$ higher survival probability), we found-in order of ranking-NTRK1, EPHA5, INSRR, EPHA10*, EPHA7, EPHB3, EPHB6*, MST1R, IGF1R, ERBB3*, and KDR (Fig. 2 bottom subset). Asterisks denote members that are classified as pseudokinases, since they exhibit minimal or no kinase activity. Despite lacking enzymatic function, pseudokinases display regulatory and/or signaling roles via alternative mechanisms (reviewed in [20]). Importantly, the roles for some of these RTKs in promoting neuronal differentiation in general and better neuroblastoma prognosis (e.g., NTRK1, INSRR, EPHB6, and ERBB3) have been previously established, thus confirming the reliability of our approach. Importantly, we also identified multiple RTKs with no previous link to neuroblastoma tumorigenesis or known association with clinical outcome, thus constituting 


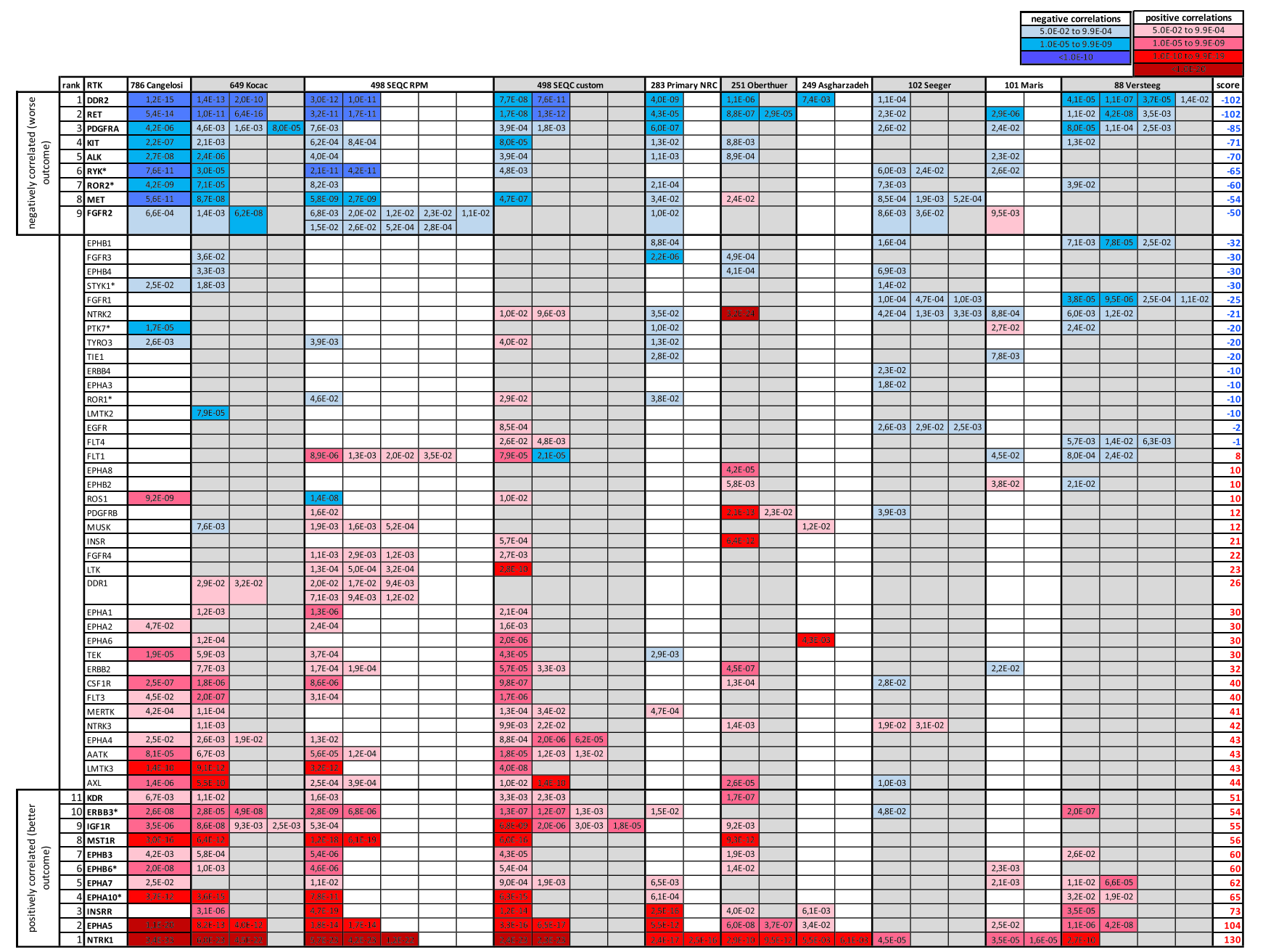

Fig. 2 Systematic analysis of RTK expression correlation to neuroblastoma patient survival. Association of RTK gene expression to neuroblastoma patient survival sorted by score. Significant Bonferroni-adjusted $p$ values $(p$ value $<0.05)$ from the correlation of neuroblastoma patient survival probability to RTK gene expression for every member of the RTK superfamily (58) across 10 publicly available datasets were annotated and ranked (see main text and Methods section for details). The figure is presented as a pseudo-heatmap table, highlighting the most significant negatively (top subset; blue)

novel and potentially valuable markers for classification and/or prognostic strategies.

\subsection{RTKs associated to a better outcome}

Receptor tyrosine kinases showing consistent correlations to better patient survival probability may be useful prognostic markers in neuroblastoma and indicate pathways involved in neural crest differentiation. This is the case of NTRK1/ TrkA, whose expression and functions have extensively been associated to neuroblastoma spontaneous regression/ differentiation and to better outcomes (reviewed in [21, 22]). Expressions of EPHB6 [23, 24] and ERBB3 [25, 26] have and positively (bottom subset; red/pink) correlated RTK members. Top subset: RTKs with -50 points or less, corresponding to RTKs that show a significant adjusted $p$ value in 5 or more independent datasets correlating to reduced patient survival. Bottom subset: RTKs with 50 points or more, corresponding to RTKs that show a significant adjusted $p$ value in 5 or more independent datasets correlating to increased patient survival. * Asterisks denote members known or predicted to be pseudokinases

also been previously associated with better prognosis. On the other hand, a number of studies have characterized the prooncogenic activities of IGF1R in neuroblastoma cell lines and tumor models [27-30]. Therefore, it was very surprising to find a very robust correlation of IGF1R expression to a better survival probability in 5 independent patient datasets. Among the several cellular functions induced by this RTK in neuroblastoma cells, a major one is cell differentiation [31], suggesting that under specific in vivo contexts, IGF1R suppressive activities might dominate over pro-oncogenic activities observed in cell culture. The related INSRR RTK also exhibited a strong positive correlation to survival in 7 out of 10 cohorts, ranking in the 3 rd position overall. The 
INSRR genetic locus is found in the opposite DNA strand of NTRK1. Interestingly, these genes have promoters and transcription start sites less than $2 \mathrm{~kb}$ apart in a head-to-head orientation [32]. Furthermore, expression of both genes has been shown to be co-regulated in neural crest-derived neurons [33] and in neuroblastoma tumor samples [34].

Finally, KDR (or VEGFR2) is an established proto-oncogene in several solid tumor models, including neuroblastoma $[35,36]$, due to its central role orchestrating tumor neoangiogenesis. Thus, our finding of its genetic association with improved outcome is unexpected. One possible explanation for this might rely on the alternative splicing variant sVEGFR2, which acts as a secreted endogenous inhibitor of angiogenesis. In this context, Becker et al. [37] demonstrated MYCN-dependent downregulation of sVEGFR2 in advanced stages neuroblastoma tumor samples. Thus, in low-risk neuroblastoma patients, higher expression of VEGFR2 (in the form of the sVEGFR2 variant) might indeed be correlated to a better survival probability. Alternatively, expression of the ligand VEGF has also been correlated to neuroblastoma differentiation and to a favorable prognosis in neuroblastoma patients [38], suggesting a neuroblastoma cell-intrinsic tumor-suppressive role for VEGF/KDR signaling, independently of its angiogenic function on endothelial cells. Overall, the roles of KDR-mediated signaling in neuroblastoma cell homeostasis await future elucidation.

To the best of our knowledge, there are no current reports associating EPHA5, EPHA10, EPHA7, EPHB3, or MSTIR to neuroblastoma pathogenesis. Interestingly, the fact that 5 different members of the EPH RTK subfamily were represented within the top 7 scores of our analysis points to a likely redundant but essential function of this RTK family as modulators of neuroblastoma cell homeostasis and/or differentiation. Future efforts should consider the incorporation of such markers into neuroblastoma tumor diagnosis and classification protocols.

\subsection{RTKs associated to a worse outcome}

Regarding RTKs that showed a significant negative correlation (higher expression $=$ lower survival probability) across at least 5 cohorts, we found RET, DDR2, PDGFRA, KIT, ALK, RYK*, ROR2*, MET, and FGFR2 (Fig. 2 top subset). Once more, the fact that some of such RTKs have previously been described as important players in neuroblastoma tumor biology (e.g., ALK, KIT, MET, and RET) again validates this approach. More importantly, RTKs that have remained poorly studied in the context of neuroblastoma pathogenesis, such as DDR2 and PDGFRA, are now revealed as very robust and potentially critical modulators of neuroblastoma.

Our systematic analysis is based on correlations of patient survival probability to mRNA expression of the different RTK superfamily members. It is well known that in many cases, mRNA levels do not necessarily reflect protein abundance $[39,40]$. In recent years, several proteomic and phosphoproteomic studies on neuroblastoma cells and models have been carried out, contributing to our better understanding of the kinases and pathways underlying this malignancy. On this regard, DeNardo et al. [41] performed a quantitative phosphoproteomic profiling of the neuroblastoma cell line NB10 versus a neural progenitor cell line (NPC) as a control. This analysis demonstrated significant enrichment of phosphorylated RTK peptides and downstream mediators of signaling in the NB10 cells. Among such phosphorylated RTKs, they found-in order of relative increase over the control-RET, DDR2, ROR2, IGF1R, EPHA2, and FGFR2. Subsequent work including phosphoproteomic and sophisticated informatic analyses of protein-protein interaction on 4 neuroblastoma cell lines under different experimental conditions [42] identified significant enrichment of phosphorylated peptides from several RTKs in the endosomal compartment on at least 2 independent cell lines. These RTKs included-in relative order of magnitude-DDR2, ALK, KIT, RET, EGFR, PDGFRA, FGFR1, IGF1R, EPHB3, EPHA2, and EPHB2. Taken together, these studies not only confirm the expression at the protein level for many of our top candidate RTKs in neuroblastoma cells, but also their relatively increased phosphorylation, which is generally associated to activation, a feature further supported by the concurrent phosphorylation of several downstream signaling components. Thus, mRNA expression does seem to reflect protein expression and function in this particular context. Future efforts should examine to which extent these observations are maintained in patient-derived tumor samples and whether there are expression and function correlations to disease stage and/or to specific cell populations within these tumors.

Given that these RTKs may constitute potential pharmacological targets for neuroblastoma treatment, an in-depth review of the current literature on such receptors will be the focus of the following sections. Our new identification of RTKs whose expression strongly correlates with poor neuroblastoma survival across multiple independent clinical cohorts (Fig. 2 top subset) opens new avenues for development of novel therapeutic interventions targeting these receptors. Below we review the current literature and detail potential context-dependent oncogenic functions of the top ranked RTKs from our analysis.

\subsubsection{RET}

The proto-oncogene RET ("rearranged during transfection") encodes an RTK for the glial cell line-derived neurotrophic factor family of ligands (GDNF, NRTN, ARTN, PSPN, and GD15). Ligand-receptor binding and specificity is afforded by one of five "GDNF family receptor alpha" (GFR $\alpha 1$, 


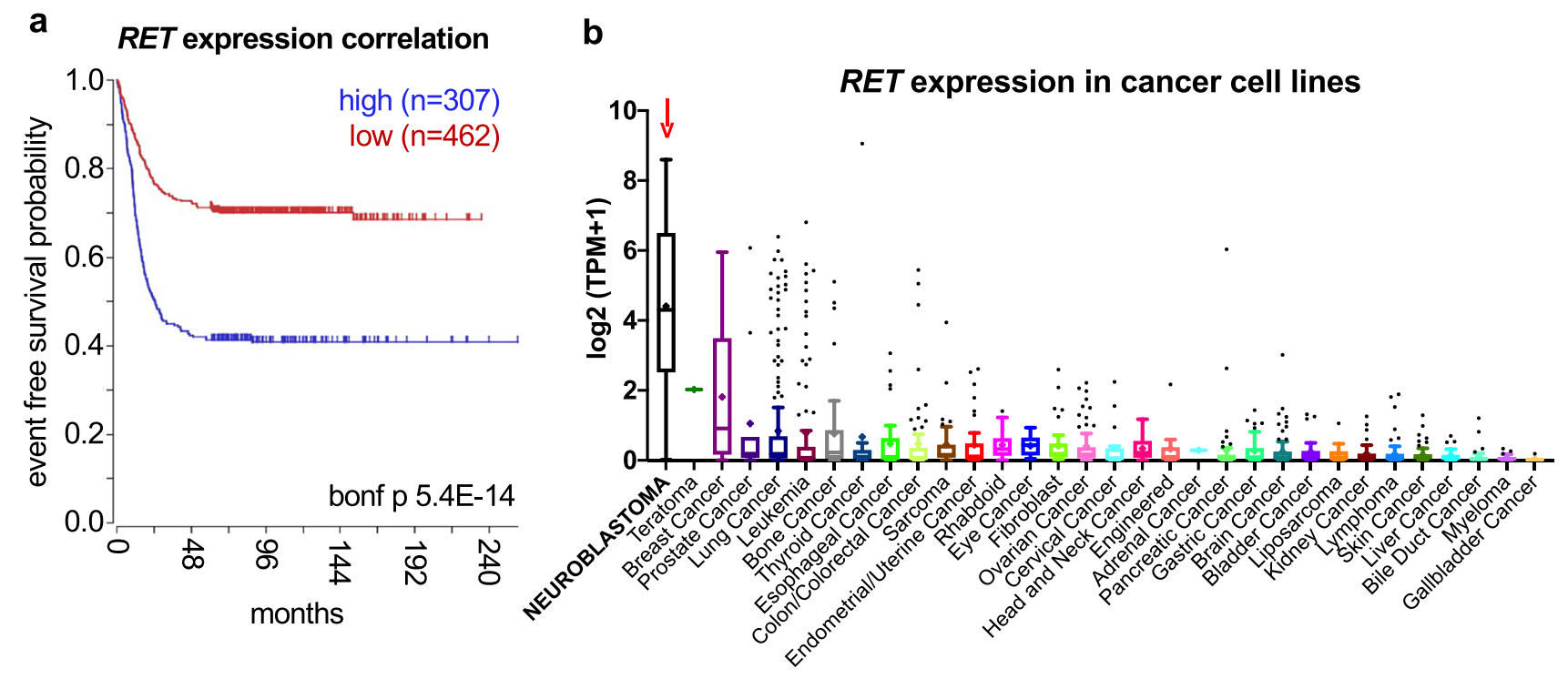

b

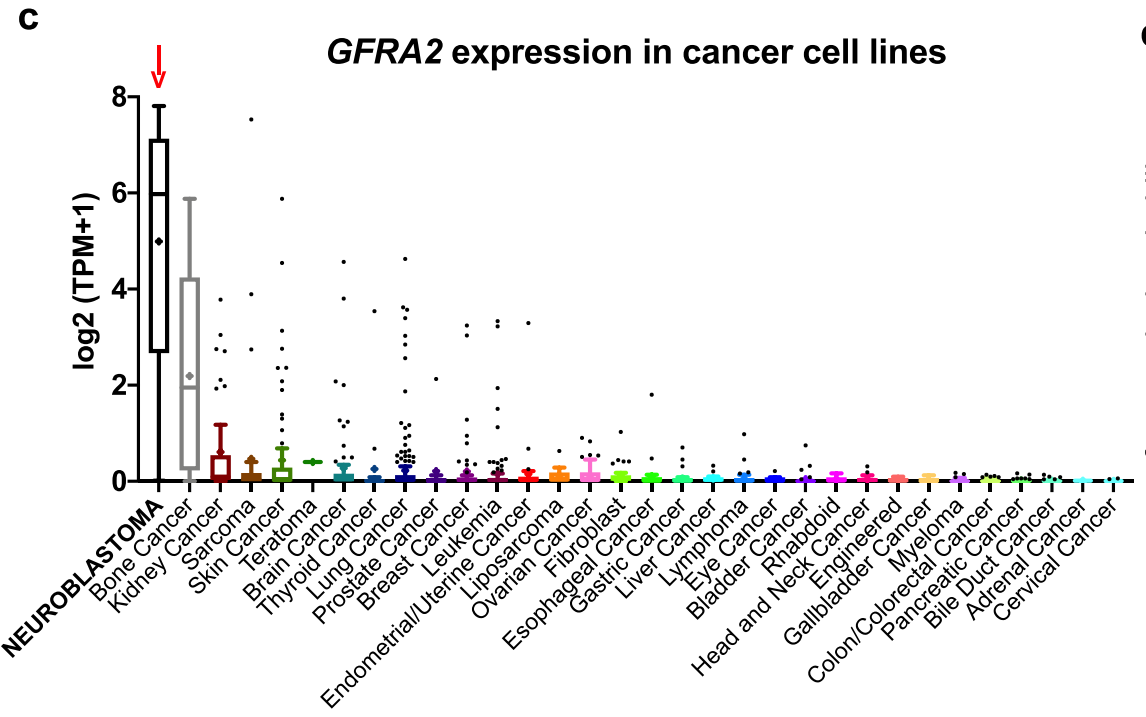

d GFRA2 expression correlation

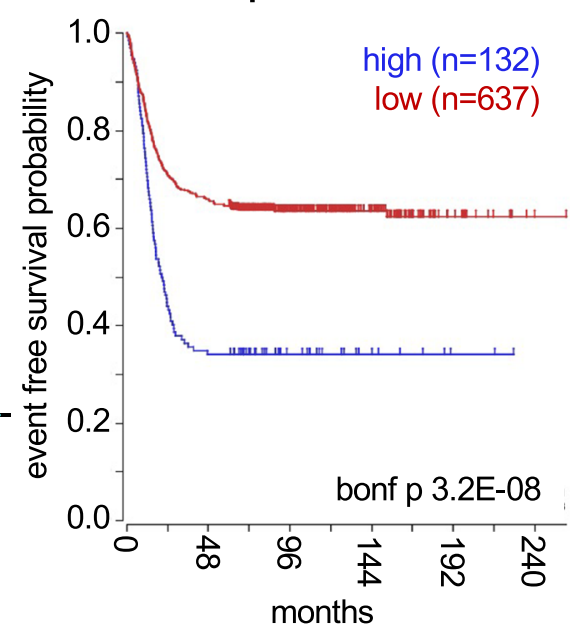

e

\begin{tabular}{|c|c|c|c|c|c|c|c|c|c|c|c|c|c|}
\hline & \multicolumn{3}{|c|}{ RET } & GFRA1 & \multicolumn{3}{|c|}{ GFRA2 } & \multicolumn{3}{|c|}{ GFRA3 } & \multicolumn{2}{|c|}{ GFRA4 } & \multirow[t]{2}{*}{ GFRAL } \\
\hline Cangelosi 786 & $5,4 \mathrm{E}-14$ & & & & $3,2 \mathrm{E}-08$ & & & $5,7 \mathrm{E}-09$ & & & & & \\
\hline Kocak 649 & $1,0 \mathrm{E}-11$ & $6,4 \mathrm{E}-16$ & & & $3,6 \mathrm{E}-10$ & $4,1 \mathrm{E}-08$ & $2,2 \mathrm{E}-06$ & $2,0 \mathrm{E}-10$ & $2,4 \mathrm{E}-10$ & $2,1 \mathrm{E}-09$ & & & \\
\hline SEQC 498 RPM & $3,2 \mathrm{E}-11$ & $1,7 \mathrm{E}-11$ & & & $8,9 \mathrm{E}-05$ & $1,0 \mathrm{E}-04$ & $1,0 \mathrm{E}-04$ & $3,5 \mathrm{E}-12$ & & & $2,4 \mathrm{E}-04$ & $2,5 \mathrm{E}-04$ & \\
\hline SEQC 498 custom & $1,7 \mathrm{E}-08$ & $1,3 \mathrm{E}-12$ & & $2,5 \mathrm{E}-02$ & $2,1 \mathrm{E}-03$ & $2,5 \mathrm{E}-03$ & & $3,0 \mathrm{E}-10$ & $1,8 \mathrm{E}-10$ & $6,7 \mathrm{E}-11$ & & & \\
\hline NRC 283 & $4,3 \mathrm{E}-05$ & & & & $2,5 \mathrm{E}-03$ & & & $1,3 \mathrm{E}-04$ & & & & & \\
\hline Oberthuer 251 & $8,8 \mathrm{E}-07$ & $2,9 E-05$ & & & & & & $2,6 \mathrm{E}-06$ & $9,7 \mathrm{E}-06$ & $2,2 \mathrm{E}-06$ & & & \\
\hline Asgharzadeh 249 & & & & $2,1 \mathrm{E}-02$ & $1,6 \mathrm{E}-02$ & & & $1,5 \mathrm{E}-02$ & & & & & \\
\hline Seeger 102 & $2,2 \mathrm{E}-02$ & & & $9,4 \mathrm{E}-03$ & & & & $8,3 \mathrm{E}-07$ & & & & & \\
\hline Maris 101 & $3,0 \mathrm{E}-06$ & & & & & & & & & & & & \\
\hline Versteeg 88 & $1,2 \mathrm{E}-02$ & $4,1 \mathrm{E}-08$ & $3,4 \mathrm{E}-03$ & & & & & $1,1 \mathrm{E}-03$ & & & & & \\
\hline score & & -102 & & 10 & & -46 & & & 102 & & - & 1 & 0 \\
\hline & & & posi & ive corre & ation & & nega & ive corre & ation & & & & \\
\hline & & & 5.01 & -02 to 9.9 & -04 & & $5.0 \mathrm{E}$ & -02 to 9.9 & -04 & & & & \\
\hline & & & $1.0 \mathrm{E}$ & -05 to 9.9 & $E-09$ & & $1.0 \mathrm{E}$ & .05 to 9.9 & -09 & & & & \\
\hline & & & & $\mathrm{al}<1.0 \mathrm{E}$ & & & & $\mathrm{al}<1.0 \mathrm{E}$ & & & & & \\
\hline
\end{tabular}


४Fig. 3 RET signaling components in neuroblastoma patient samples and cell lines. a Representative Kaplan-Meier plot for the correlation of RET expression to patient survival probability from R2 (Cangelosi 786 cohort). RET was the top negatively correlated RTK (Fig. 2 top subset), indicative of its role in NB pathogenesis and aggressiveness (as previously shown by others; see main text for details). "bonf p" = Bonferroni adjusted $p$ value. b RET mRNA expression across different cancer cell lines (CCLE) showing a high and specific average RET expression in neuroblastoma cell lines (red arrow) as compared to all other cancer cell lines. c GFRA2 mRNA expression across different cancer cell lines (CCLE) showing a high and specific average expression in neuroblastoma cell lines (red arrow) as compared to all other cancer cell lines. d Representative Kaplan-Meier plot for the correlation of GFRA2 expression to patient survival probability obtained from R2 (Cangelosi 786 cohort). "bonf p"=Bonferroni adjusted $p$ value. e Association of RET co-receptors mRNA expression to neuroblastoma patient survival. Significant Bonferroniadjusted $p$ values $(p$ value $<0.05$ ) correlating patient survival probability to GFRA co-receptors across 10 publicly available datasets were annotated and ranked (see Methods and Fig. 2 for details). The panel is presented as a pseudo-heatmap table

GFR $\alpha 2$, GFR $\alpha 3$, GFR $\alpha 4$, and GFR $\alpha \mathrm{L}$ ) co-receptors. The GDNF/RET signaling axis plays a major role during sympathetic and enteric nervous systems development, where it mediates proliferation, migration, and differentiation (reviewed in [43-45]). RET is an oncogene and constitutive activation results in human multiple endocrine neoplasia (MEN) syndromes 2A and 2B and familial medullary thyroid carcinoma [46]. Pioneer studies reporting RET expression and function in neuroblastoma models date back to more than 30 years ago [47-49], but the actual implications of this kinase in neuroblastoma pathogenesis have recently started emerge. Initially, Iwamoto et al. [50] reported neuroblastoma development in a transgenic mouse that carried the $R E T$ oncogene driven by a mouse metallothionein regulatory element. Additional reports using cell lines support a role for GDNF/RET signaling in differentiation, migration, and metastasis [51-56]. Recently, using neuroblastoma models carrying activating $A l k$ mutations in the context of MYCN overexpression, Cazes et al. [57] demonstrated that RET is upregulated in an ALK-dependent fashion. RET inhibition by the small-molecule vandetanib (ZD-6474) significantly reduced tumor growth in this genetically engineered mouse model (GEMM). In a follow-up study from the same group [58], an oncogenic RET mutation in the context of the THMYCN mouse model recapitulated the phenotype seen in mutant $A L K / \mathrm{TH}-\mathrm{MYCN}$ mice. Furthermore, a synergistic in vivo antitumor effect was shown by concomitant RET (vandetanib) and ALK inhibition (crizotinib). In parallel, Zhang et al. [59] characterized the effect of another RET inhibitor, cabozantinib (XL184), on in vitro and in vivo neuroblastoma paradigms. Subsequent studies from the same group found comparable results when using the small-molecule RET/ multikinase inhibitor RXDX-105 [60] or the RET/multikinase inhibitor regorafenib (BAY 73-4506) [61]. Notably, the effect of regorafenib on in vitro and in vivo neuroblastoma models had been previously reported by Chen et al. [62]. Moreover, regorafenib was clearly established as a RET signaling inhibitor in neuroblastoma cell lines, and its tumor suppressant effect was validated in vivo in a xenograft tumor system and in the immuno-competent TH-MYCN transgenic mouse model. In our analysis, RET (together with DDR2) ranked as the top RTK whose expression robustly correlated to an unfavorable outcome across the majority of neuroblastoma patient cohorts (Fig. 2 top subset and Fig. 3a). We additionally analyzed RET expression across 1378 cancer cell lines from the Cancer Cell Line Encyclopedia (depmap portal) [63-65] and found that neuroblastoma cell lines display the highest mean RET mRNA expression (Fig. 3b).

Despite the findings above, other groups have presented data pointing to a role for RET in neuroblastoma differentiation in the context of retinoic acid (RA)-induced differentiation [66-72]. In this line, RET is proposed to act as a tumor suppressor by promoting a transcriptional program leading to a terminally differentiated (non-malignant) neuronal phenotype. It is worth noting that most of these analyses have been performed in the context of in vitro cell differentiation assays with specific neuroblastoma cell lines. While more physiologically relevant models await investigation, a possible explanation might rely on the cell context-dependent expression of GFR $\alpha$ co-receptors. GFRA2 is highly and specifically expressed in neuroblastoma cell lines (Fig. 3c and [73]) and promotes their proliferation [73]. Additionally, GFR $\alpha 2$ has been proposed as a potential target for antibody-/CAR T cell-based therapies against neuroblastoma [74]. Lastly, GFRA2 (Fig. 3d-e) and its ligand NRTN (not shown) both showed significant association to reduced survival in 5 independent patient datasets, while GFRA3 exhibited the opposed correlation in 9 out of 10 cohorts (Fig. 3e). Therefore, a cell-type specific GFR $\alpha 2 / G F R \alpha 3$ ratio could indeed determine the tumor promoting vs. tumor suppressing behavior of RET. This hypothesis is further supported by expression correlation data across 12 publicly available neuroblastoma datasets [75], which showed significantly positive associations of RET with GFRA2, but negative in the case of GFRA3. Other signaling components could also contribute to this decision. For instance, the scaffold protein PAG1 can modulate the localization and function of the Src family kinases FYN and LYN and ultimately help finetune the proliferation vs. differentiation behavior of neuroblastoma cells [76, 77]. Altogether, these conflicting results highlight the need for careful tumor modeling and appreciation of the context-dependent roles of RTKs in general.

In summary, a growing body of literature suggests that RET plays an important role promoting neuroblastoma tumorigenesis and aggressive phenotypes. As described above, several groups have started to focus on targeting RET signaling as a novel strategy against neuroblastoma tumors, 
a

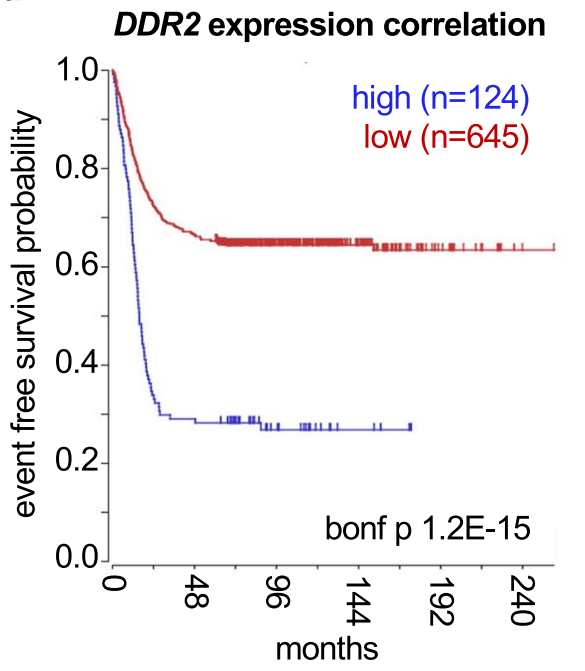

b

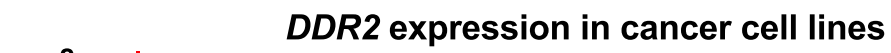

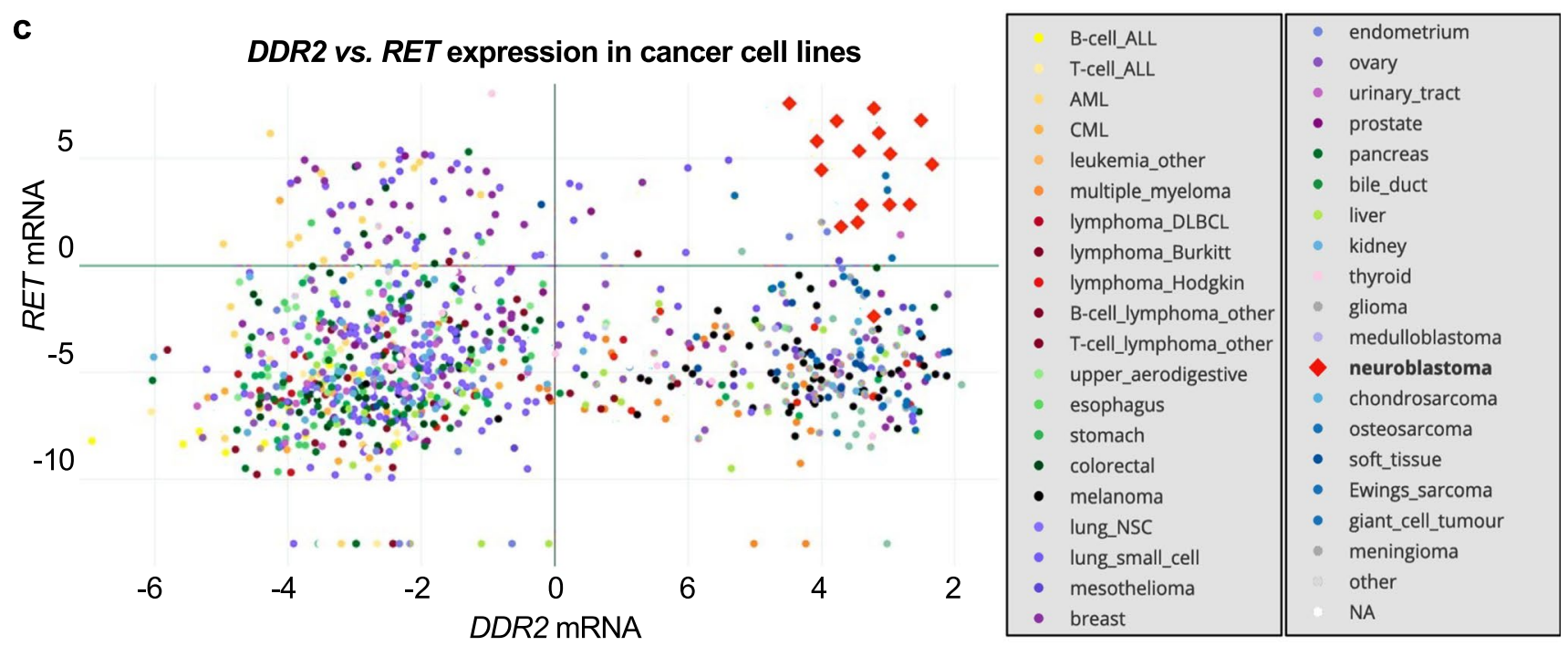

d

TWIST1 vs. DDR2 mRNA expression

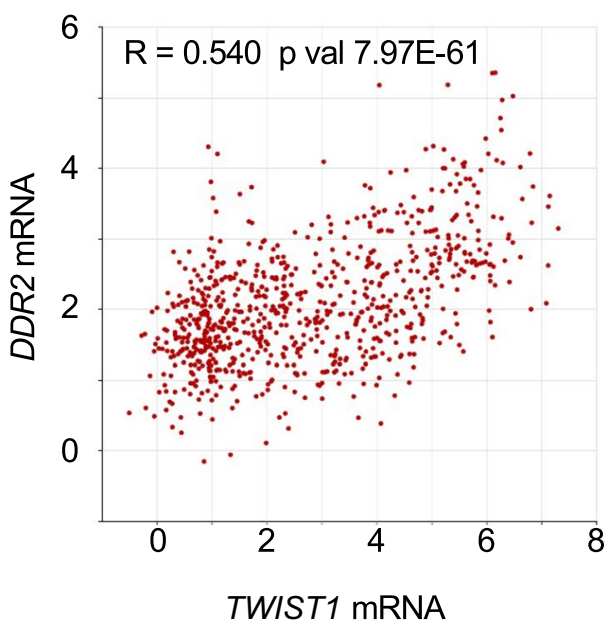

\begin{tabular}{|l|r|r|r|}
\hline \multicolumn{4}{|c|}{ DDR2 to TWIST1 expression correlation } \\
\hline & \multicolumn{1}{|c|}{ patients } & R & \multicolumn{1}{|c|}{ p val } \\
\hline Cangelosi & $786^{*}$ & 0,540 & $7,97 \mathrm{E}-61$ \\
\hline Kocak & 649 & 0,544 & $3,26 \mathrm{E}-51$ \\
\hline & & 0,510 & $3,43 \mathrm{E}-44$ \\
\hline & & 0,501 & $1,31 \mathrm{E}-42$ \\
\hline SECQ-RPM & & 0,469 & $8,71 \mathrm{E}-37$ \\
\hline SEQC-custom & $498^{*}$ & 0,550 & $1,20 \mathrm{E}-40$ \\
\hline & & 0,548 & $2,33 \mathrm{E}-40$ \\
\hline & $498^{*}$ & 0,588 & $1,39 \mathrm{E}-47$ \\
\hline NRC-primary & & 0,586 & $3,49 \mathrm{E}-47$ \\
\hline Oberthuer & & 0,568 & $7,83 \mathrm{E}-44$ \\
\hline & & 0,551 & $5,79 \mathrm{E}-41$ \\
\hline Asgharzadeh-TARGET & 283 & 0,638 & $8,30 \mathrm{E}-34$ \\
\hline Seeger & 251 & 0,485 & $3,10 \mathrm{E}-16$ \\
\hline Maris & & 0,469 & $3,93 \mathrm{E}-15$ \\
\hline Versteeg & 249 & 0,594 & $4,01 \mathrm{E}-25$ \\
\hline & 102 & 0,378 & $8,88 \mathrm{E}-05$ \\
\hline & 101 & 0,460 & $1,27 \mathrm{E}-06$ \\
\hline & 88 & 0,646 & $1,05 \mathrm{E}-11$ \\
\hline Capasso & & 0,607 & $3,50 \mathrm{E}-10$ \\
\hline & & 0,493 & $1,06 \mathrm{E}-0$. \\
\hline & & 0,389 & $1,78 \mathrm{E}-04$ \\
\hline & 27 & 0,630 & $4,31 \mathrm{E}-04$ \\
\hline & & 0,627 & $4,66 \mathrm{E}-04$ \\
\hline & & 0,616 & $6,26 \mathrm{E}-04$ \\
\hline & & 0,589 & $1,22 \mathrm{E}-03$ \\
\hline
\end{tabular}


4Fig. $4 D D R 2$ expression in neuroblastoma patient tumor samples and cell lines. a Representative Kaplan-Meier plot for the correlation of $D D R 2$ expression to patient survival probability obtained from R2 (Cangelosi 786 cohort). "bonf $\mathrm{p} "=$ Bonferroni adjusted $p$ value. b DDR2 mRNA expression across different cancer cell lines (CCLE) showing a relatively high average expression (top 2) in neuroblastoma cell lines (red arrow) as compared to all other cancer cell lines. c Expression of RET vs. DDR2 mRNA $(\log 2(\mathrm{TPM}+1))$ across cancer cell lines (CCLE), demonstrating a high and exclusive co-expression of both markers in neuroblastoma cell lines. d DDR2 and TWIST1 expression are highly correlated in every neuroblastoma patient dataset. Left panel: representative plot of DDR2 and TWIST1 expression correlation analysis from R2 (Cangelosi 786 cohort). Right panel: correlation coefficients $(\mathrm{R})$ and corresponding $p$ values for all available DDR2 to TWIST1 expression associations from 11 independent patient datasets (R2), predicting a transcriptional/functional codependency, as previously described in other models (see main text for details). * Asterisks denote datasets containing the same patient cohort but analyzed by different techniques or analytical methods

showing promising results that demand further efforts and clarification.

\subsubsection{DDR2}

The discoidin domain receptor family of RTKs is composed by 2 members, DDR 1 and DDR2. The natural ligand for DDR receptors is collagen, and upon ligand binding, these RTKs become activated with slow and sustained kinetics $[78,79]$. DDR receptors are implicated in many developmental and physiological roles, such as mammary gland development (for DDR1 [80]) or proper bone growth (for DDR2 [81]), while their deregulation may underlay certain types of cancer (reviewed in [82-85]). Somatic mutations of DDR2 are present in 3-4\% of patients with squamous cell lung carcinoma [86] and at comparable frequencies in cervical carcinoma, melanoma, colorectal cancer, and some head and neck cancers $[82,87,88]$. The best understood oncogenic role of DDRs is their involvement in tumor invasion and metastasis. DDRs participate in several steps of the metastatic process including activation of epithelial to mesenchymal transition (EMT), and by promoting cell migration via degradation of the extracellular matrix and tissue colonization [83].

Our present analysis establishes a highly significant and robust correlation between $D D R 2$ expression and neuroblastoma patient outcome in 9 out of 10 patient datasets, ranking on the top of our list together with RET (Fig. 2 top subset and Fig. 4a). We further investigated $D D R 2$ expression in the Cancer Cell Line Encyclopedia (CCLE) and observed that neuroblastoma cell lines ranked in the top 2nd position for highest average expression (Fig. 4b). Moreover, high coexpression of RET and DDR2 distinguishes neuroblastoma cell lines from virtually any other cancer cell line in the CCLE (Fig. 4c). Despite of this, we did not observe a very high expression correlation between DDR2 and RET in the
R2 tumor datasets (not shown), which could suggest expression in different tumor cell subpopulations. This idea is further supported by recent transcriptional characterization of paired mesenchymal vs. adrenergic isogenic cells from human neuroblastoma tumors [89]. This work established a mesenchymal gene signature set of 485 mRNAs and a 369 -adrenergic gene signature. Importantly, $D D R 2$ was one of the mesenchymal signature genes, while RET and $A L K$ were listed in the adrenergic set. In line with this, Siaw et al. recently showed that loss of RET promotes mesenchymal identity in neuroblastoma cells [56]. Moreover, the authors also observed that RET expression and activity are directly regulated by ALK.

Interestingly, $D D R 2$ is a key transcriptional target of TWIST1 during cranial mesoderm development [90] and in ovarian cancer cells, where TWIST1-dependent DDR2 expression was critical for EMT, migration, invasion, and in vivo metastasis [91]. The TWIST1 transcription factor is a master regulator of EMT and metastasis (reviewed in [92]). Moreover, DDR2 activation promotes SNAIL1 protein stabilization and EMT of metastatic breast cancer cells [93]. It is worth noting that in neuroblastoma, TWISTI is a direct transcriptional target of MYC/MYCN [94]. In further analyses on the R2 Genomics Platform, we found very significant correlations between $D D R 2$ and TWIST1 expression in every single neuroblastoma patient dataset available (Fig. 4d). Hence, it can be hypothesized that the transcriptional axis MYCN/TWIST1/DDR2/SNAIL1 could drive high-risk neuroblastoma tumor invasion and metastasis. Finally, our analysis and literature review suggest that DDR2 may be an excellent therapeutic target in neuroblastoma, a feature that is currently being addressed in our lab.

\subsubsection{PDGFRA}

The platelet-derived growth factor receptor A (or CD140a) is an RTK expressed in a wide spectrum of cell types, exerting a range of developmental and physiological functions in mesodermal-derived tissues, such as connective tissue, blood, and mesangial cells [95, 96]. Importantly, PDGFRA signaling has been shown to contribute to the development of cranial and cardiac neural crest-derived structures (reviewed in [18]). The roles of this RTK in cancer have been extensively studied in the context of gastrointestinal stromal tumors (GIST) where activating point mutations on PDGFRA are found in 5-7\% of GIST cases [97] (reviewed in[98]). PDGFRA rearrangements (mostly FIPIL1-PDG$F R A$ fusions) are found in 10-20\% of patients with idiopathic hypereosinophilia and in some cases of systemic mastocytosis [99]. Finally, amplifications of the PDGFRA gene are observed in 5-10\% cases of glioblastoma multiforme. PDGFRA amplification has also been observed in oligodendrogliomas [100], esophageal squamous cell carcinoma 
[101], and arterial intimal sarcomas [102]. Thus, overexpression and/or hyperactivation of PDGFRA plays a role in the pathogenesis of multiple tumor types (reviewed in [98]).

In relation to neuroblastoma, Matsui et al. [103] reported the expression of PDGFRA transcripts and protein in several neuroblastoma cell lines, although Beppu et al. [104] was only able to detect PDGFRA expression in 1 (SH-SY5Y) out of 7 neuroblastoma lines. Also, a potential role for PDGFRA has been suggested during in vitro differentiation of SH-SY5Y cells towards a neuronal phenotype [105]. In our analysis of expression correlation, PDGFRA ranked in the 3rd top position, showing statistically significant correlation with poor survival in 8 out of 10 cohorts (Fig. 2 top subset and Supplementary Fig. 2a). Furthermore, analysis of $P D G$ FRA mRNA expression in the Cancer Cell Line Encyclopedia showed that neuroblastoma cell lines express relatively high levels of this RTK, ranking in 2nd position in average overall (Supplementary Fig. 2b). Therefore, and given the established roles for this receptor in other tumor types, our data implicates this RTK as a potential therapeutic target in neuroblastoma. Several relatively non-specific inhibitors of PDGFRA (i.e., imatinib and sunitinib) are currently in clinical trials, and as more specific and potent PDGFRA inhibitors are developed, our findings support preclinical testing in neuroblastoma tumor models.

\subsubsection{KIT}

The KIT proto-oncogene (c-KIT aka CD117) encodes the RTK for the stem cell factor (SCF) ligand. SCF/c-KIT signaling contributes to organ development and homeostasis, in part by maintaining the stemness of progenitor cells in several adult tissues [106, 107]. Although KIT activating mutations have been found to drive transformation in GIST, acute myeloid leukemia, mast cell leukemia, and melanoma, no gain-of-function mutations on KIT have been reported in neuroblastoma [108] [109]. Initial studies from Cohen et al. [110] analyzed SCF/KIT expression in neuroblastoma tumor samples and cell lines. This and subsequent reports [111-113] confirmed a role for SCF/KIT signaling driving cell growth and proliferation. Vitali et al. [114] established a positive correlation between KIT and MYCN expression and found that KIT-mediated proliferation in vitro was sensitive to the multikinase inhibitor imatinib. Moreover, Uccini et al. [115] observed that in primary neuroblastoma tumor samples, SCF/KIT expression correlated to MYCN amplification, and worse overall survival. A small subpopulation of cancer stem cells characterized by high expression of c-KIT was detected from several tumor samples and cell lines [116]. This was further investigated by Lau et al. [117], who demonstrated that $\mathrm{KIT}^{+}$cells are generated de novo during neuroblastoma progression and may contribute to neuroblastoma proliferation. $\mathrm{KIT}^{+}$cells expressed higher levels of neural crest and stem cell markers and displayed a more aggressive phenotype and in vivo self-renewal capacity compared to $\mathrm{KIT}^{-}$subpopulations. However, other reports suggest that expression of KIT statistically correlated to a better prognosis in neuroblastoma tumor samples [118, 119]. Overall, our expression-to-survival correlation data (Fig. 2 top subset), together with several recent studies, suggest a role for this RTK as a relevant mediator of neuroblastoma tumor progression and resistance/relapse. Further studies on KIT functions in neuroblastoma and the impact of specific inhibitors on tumor stemness and metastasis are warranted.

\subsubsection{ALK}

The "anaplastic lymphoma tyrosine kinase" receptor, ALK, is altered by gain-of-function point mutations in half of familial neuroblastoma cases ( $\sim 1 \%$ of total cases), and in around $9 \%$ of sporadic neuroblastoma, climbing up to $14 \%$ in high-risk patients [11, 120-122]. As mentioned above, the roles of ALK in neuroblastoma pathogenesis have been extensively characterized, with several reviews published in recent years. Hence, for further reading on this specific topic, the reader is kindly referred to [123-125].

\subsubsection{RYK and ROR2}

The RYK, ROR, PTK7, and MUSK families share a unique characteristic by serving as receptors for ligands of the WNT family (Fig. 1b) [126-129]. Except for MUSK, all of them are classified as pseudokinases. The function of these WNT-binding receptors is essential for several developmental processes (for complete reviews on RYK/ROR2 biology in health and cancer, see $[6,130,131])$. Increasing studies implicate these pseudokinases in many aspects of tumor physiology including self-renewal, migration/metastasis, and drug resistance [6]. Although most of such data derive from in vitro models using cancer cell lines, in vivo experimental data supporting oncogenic roles for ROR2 have been reported in melanoma [132], renal cell carcinoma [133], ovarian cancer [134], and breast cancer [135], as well as for RYK in gastric [136] and ovarian cancer [137].

Surprisingly, while the roles for WNT signaling in neuroblastoma have been extensively studied (for recent reviews, see [138, 139]), how RYK and ROR2 modulate WNT in neuroblastoma remains largely unexplored. RYK can act as a receptor for WNT5A and other WNT family ligands that drive neural crest migration and differentiation. One study demonstrated that $R Y K$ mRNA was detected across a panel of 25 neuroblastoma cell lines [140]. The RTK genes RORI and $R O R 2$ were originally cloned form the neuroblastoma cell line SH-SY5Y [141]. Wnt/Ror2 signaling modulates the migration of neural crest cells during Xenopus development [142] and is hypothesized to a play similar roles in mammals 
[140]. Recently, Dave et al. confirmed ROR1 and ROR2 expression in neuroblastoma cell lines and patient-derived tumor samples [143]. This group showed that anti-ROR1 antibodies could target neuroblastoma cells for natural killer (NK)-mediated cell killing, while CAR T cells targeting ROR $1^{+}$neuroblastoma cells are currently under development [144]. Our analysis of gene expression from neuroblastoma tumor datasets uncovered a significant association for $R Y K$ and ROR2 — but not for RORI - to a worse survival probability in 6 out of 10 cohorts (Fig. 2 top subset and Fig. 5a). Comparison of the relative expression for $R Y K$ and $R O R 1 / 2$ across clinical datasets shows overall higher average expression of $R Y K$, with $R O R I$ and ROR2 showing similarly lower levels (Fig. 5b and Supplementary Fig. 2C). Furthermore, ROR2 expression analysis in cancer cell lines (CCLE, Broad Institute) suggests a relatively high mRNA level in neuroblastoma cells, showing the highest average expression among all cancer cell lines (Fig. 5c), while ROR1 showing low specificity for neuroblastoma cell lines (Fig. $5 \mathrm{~d}$ ). Altogether, we found that $R Y K$ and $R O R 2$, but not ROR1, are robustly associated with worse outcome in neuroblastoma. This is further supported by a recent study describing a role for ROR1, but not ROR2, in retinoic acid-induced neuroblastoma differentiation [145]. Together, these data suggest that the WNT modifying pseudokinases ROR2 and RYK represent potential novel therapeutic targets for neuroblastoma treatment and that current research on immuno-therapeutic strategies against ROR1 might need to be re-evaluated in favor of ROR2 and RYK.

\subsubsection{MET}

MET (c-Met or HGFR) is the tyrosine kinase receptor for hepatocyte growth factor (HGF). This receptor-ligand interaction triggers classical RTK signaling pathways to promote cell migration, angiogenesis, and proliferation (reviewed in [146]). MET gain of function via overexpression, amplification, aberrant splicing, or mutations is associated with multiple cancer types, such as non-small cell lung carcinoma [147], gastrointestinal cancer [148], and hepatocellular carcinoma [149]. Regarding neuroblastoma, initial studies demonstrated a role for HGF/MET signaling in the migration and/or differentiation of neural crest cell-derived structures [150]. More direct evidence by Hecht et al. [151] characterized the expression and signaling mechanisms of HGF/MET in cultured neuroblastoma cell lines. Although they did not observe any effects on in vitro proliferation, the authors reported a very clear role for HGF/MET signaling in migration/invasion of neuroblastoma cells, both in vitro and in vivo. The same group also showed that NTRK2 activation preceded and mediated HGF/MET upregulation in neuroblastoma cell lines [152]. Furthermore, they also found that sublethal irradiation led to upregulation of HGF and MET in neuroblastoma cell lines, resulting in enhanced migratory behavior [153]. Analyses for MET amplification, alternatively spliced isoforms, or protein over-expression in a small cohort of neuroblastoma tumor samples (54 samples) suggested a low prevalence of such alterations [154]. However, the development of novel small molecule inhibitors targeting c-MET activity has prompted to a re-evaluation of HGF/MET signaling in neuroblastoma and other cancer paradigms. The highly selective MET inhibitor PHA665752 was shown to significantly reduce in vitro migration and proliferation on two neuroblastoma cell lines in a dose-dependent manner [155]. The MET inhibitor EMD1214063 was also shown to efficiently reduce in vitro viability and inhibit in vivo neuroblastoma tumor growth in orthotopic xenograft mouse models [156]. Finally, MET upregulation in tumors upon pan-VEGF inhibitor therapy may act as an escape mechanism to acquire resistance and regain neoangiogenic capabilities [157]. The MET/multikinase inhibitor cabozantinib blocked neuroblastoma cell proliferation and migration and efficiently reduced in vivo neuroblastoma tumor growth and metastases in orthotopic xenograft mouse models [158]. We found a strong correlation between MET expression and a lower neuroblastoma patient survival probability in 6 out of 10 datasets (Fig. 2 top subset). In summary, our analysis together with published data highlight the need of future efforts to advance our understanding on the regulation and functions of this RTK in several aspects of neuroblastoma pathophysiology.

\subsubsection{FGFR2}

The FGFR2 gene (fibroblast growth factor receptor 2) can give rise to several alternative splicing variants, among which FGFR2b (mainly expressed in epithelial cells) and FGFR2c (in mesenchymal cells) are the most abundant (reviewed in [159]). FGFR2b and FGFR2c differentially bind specific sets of FGF ligands [160, 161]. Germline Fgfr2b-knockout mice die shortly after birth due to multipleorgan abnormalities [162, 163]. Gain of function for FGFR2 via amplification, mutation, or other mechanisms is found in multiple tumors including gastric [164], lung [165], breast [166], ovarian [167] [168] cancers, and in cholangiocarcinoma [169].

Very little is known regarding the function of FGFR2 in neuroblastoma. The FGFR2 gene is localized to the 10q26.13 locus. A high frequency of 10q loss of heterozygosity (LOH) -including FGFR2 - has been described in different tumors ([170-172]). Importantly, 10q LOH has also been described in familial neuroblastomas [173]. In this context, Lázcoz et al. [174] analyzed LOH and FGFR2 promoter hypermethylation at $10 \mathrm{q}$ in a panel of neuroblastoma tumor samples and cell lines. Although 10q LOH was observed in $18 \%$ of the cases, hypermethylation at the 

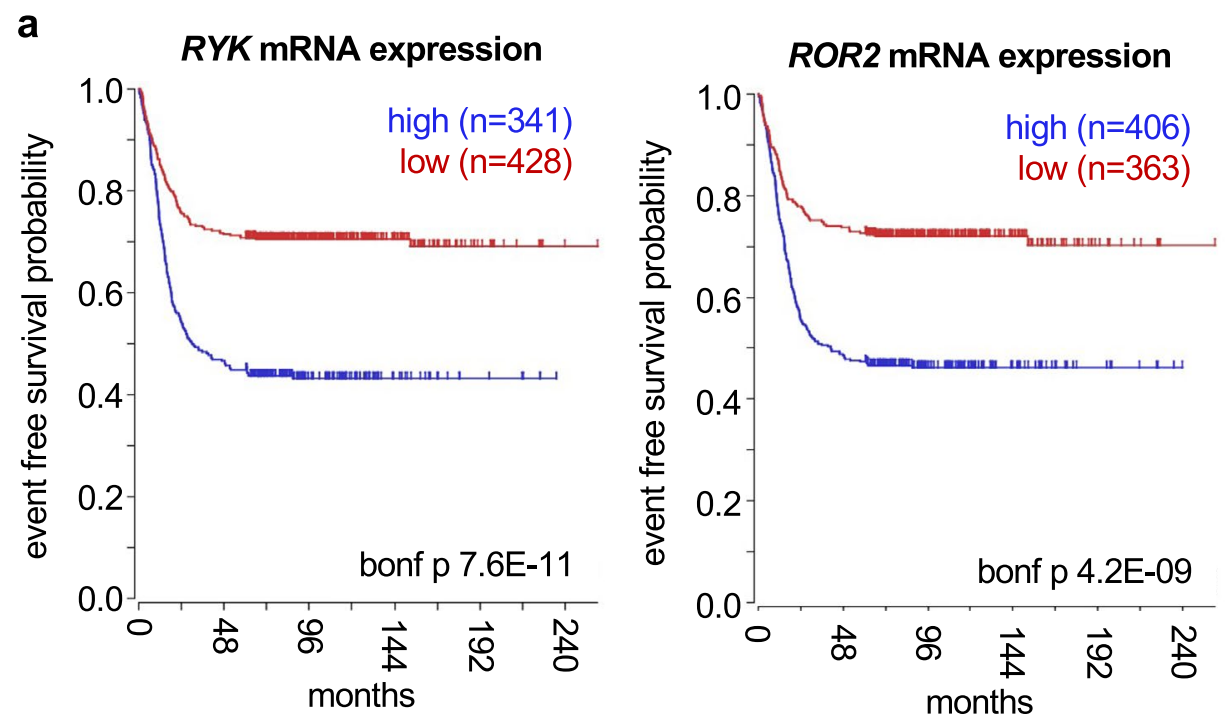

b

\section{RYK/ROR expression in tumor samples}

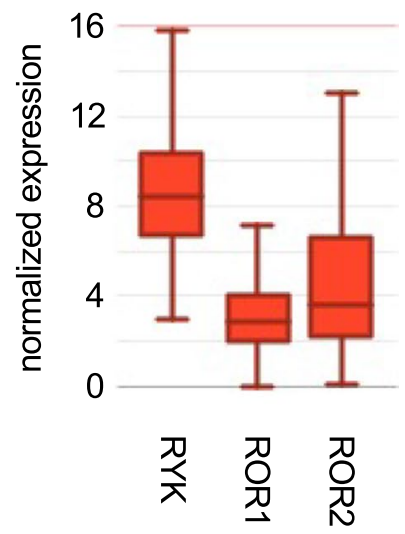

C ROR2 expression in cancer cell lines

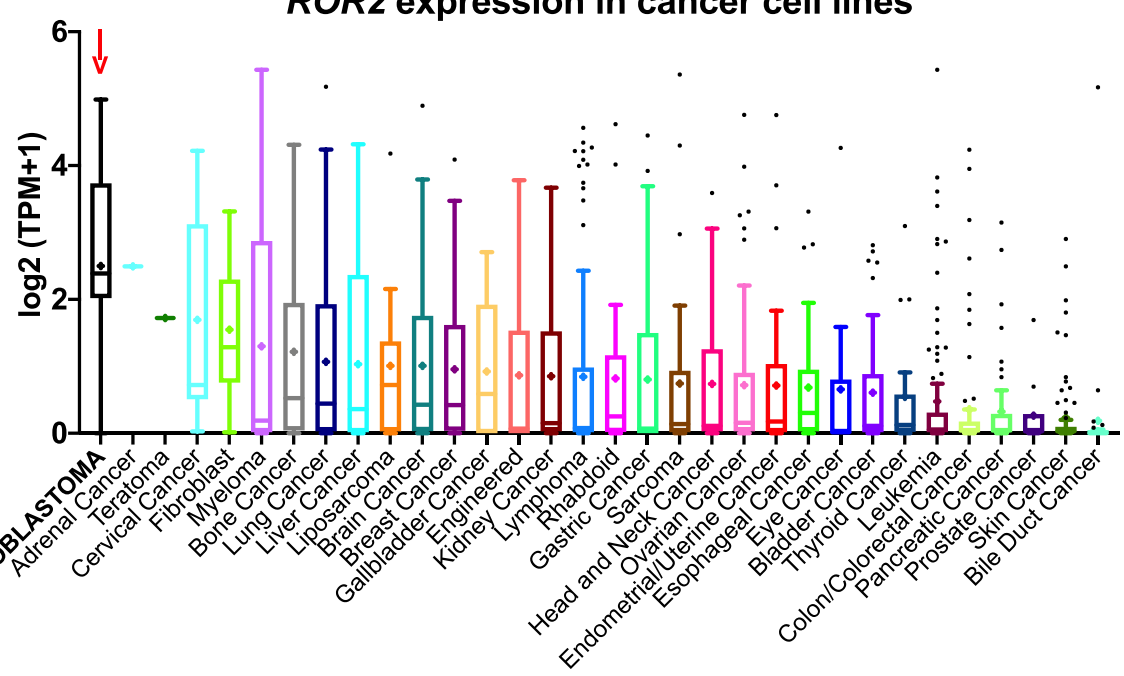

d

ROR1 expression in cancer cell lines

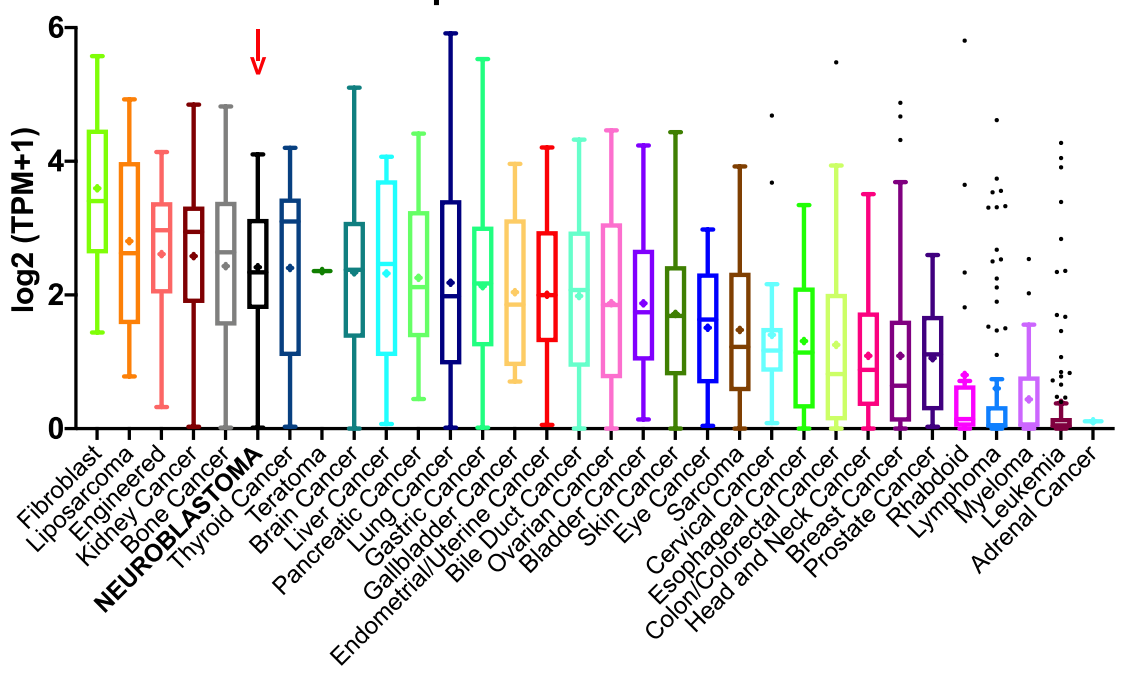


4Fig. $5 R Y$ and $R O R 2$ expression in neuroblastoma patient samples and cell lines. a Representative Kaplan-Meier plots for the correlation of $R Y K$ and ROR2 expression to patient survival probability obtained from R2 (Cangelosi 786 cohort). "bonf p"=Bonferroni adjusted $p$ value. b Representative boxplot showing average expression of $R Y K, R O R 1$, and $R O R 2$ in a neuroblastoma patient dataset (Cangelosi 786) from the R2 platform. Note the relatively higher expression of $R Y K$ (similarly observed in several cohorts; Supplementary Fig. 2C). c Expression across different cancer cell lines from the CCLE showing a relatively high and specific expression of $R O R 2$ in neuroblastoma cell lines (top average expression overall). d Expression of RORl mRNA across different cancer cell lines from the CCLE displaying less specific expression

FGFR2 promoter was not observed for any tumor sample, while FGFR2 expression was positive in all 12 cell lines included in the study, pointing to the conclusion that FGFR2 downregulation does not seem to be particularly associated with neuroblastoma pathogenesis. More recently, Salm et al. identified FGFR2 as the top candidate in a human kinomewide RNAi screen to characterize kinases that, when downregulated, sensitize neuroblastoma cells to cisplatin [175]. This work also demonstrated that MYCN activates FGFR2 transcription. We identified statistically significant correlations between increased FGFR2 and decreased survival probability in 5 out of 10 neuroblastoma patient datasets, although showing the opposite correlation in one additional cohort (Fig. 2 top subset). While the role of FGFR2 in neuroblastoma drug resistance and pathogenesis remains to be clarified, our analysis, combined with its function downstream of MYCN, suggests FGFR2 may be an effective target for highly potent small molecule inhibitors.

\subsection{Conclusions and future prospects}

Our systematic analysis of expression data for all members of the RTK superfamily across 10 well-annotated clinical cohorts of neuroblastoma patients highlights a set of important new therapeutic targets. Our methods corroborate previous independent experimental data identifying several RTKs with known roles in neuroblastoma tumorigenesis, stemness, and metastasis, but most importantly, we also reveal additional RTKs not previously associated with this cancer. We present a detailed review of the current literature for the top therapeutic candidates in the context of neural crest differentiation and neuroblastoma pathogenesis. In doing so, and for the sake of conciseness, we have not exhaustively focused on mechanistic insights of RTKs signaling, but prioritized articles showing cellular to in vivo characterizations, which provide translationally relevant concepts. Numerous recent efforts to elucidate RTKs activation, their protein interactomes, and crosstalk with other receptors and pathways [41, 42, 176-178] are also helping to define essential new dimensions of RTK biology in neuroblastoma and other cancers.
Consistent robust correlations with survival across patient cohorts for the top-ranked candidate RTKs support our hypotheses regarding their role in modulating tumor aggressiveness, metastasis, and drug resistance. We hope that translational efforts will nominate such RTKs as effective targets to be incorporated in future innovative clinical therapeutics. This work is urgently needed to advance the cure rate for children suffering from high-risk neuroblastoma.

\section{Methods}

Expression-survival correlations in R2 All the significant Bonferroni-adjusted $p$ values $(p$ value $<0.05)$ correlating neuroblastoma patient survival probability to RTK expression for every available probe of every member of the RTK superfamily across 10 publicly available datasets (KaplanMeier plots produced in R2: Genomics Analysis and Visualization Platform (http://r2.amc.nl)) were annotated, and each RTK received a score. The score of each RTK was established by assigning 10 points for every dataset showing one or more significant adjusted $p$ value ( $p$ value $<0.05)$. One additional point was assigned for every additional probe with a significant $p$ value within the same dataset, and finally, one, two, or three additional points were assigned for those $p$ values $<10^{-10},<10^{-20}$ or $<10^{-30}$, respectively. Finally, positive expression-to-survival correlations were assigned positive values (red to pink; higher survival probability), whereas negative correlations received negative scores (dark to light blue; lower survival probability). We arbitrarily established that each RTK showing a significant Bonferroniadjusted $p$ value in at least 5 independent cohorts would be considered as a candidate for further analysis. Therefore, a minimum score of 50 points (either positive or negative) was determined as the threshold of "significance" for further consideration. Tables are presented as a pseudo-heatmaps, to highlight the most significant correlations. For any given RTK, each dataset might contain 0,1 , or more probes, giving rise to 0,1 , or more possible significant correlations (with their corresponding $p$ values).

Cancer Cell Line Encyclopedia analysis Expression data of selected genes (Expression 21Q2 Public database) was downloaded from the CCLE (phases I and II), included in the Cancer Dependency Map portal (https://depmap.org/ portal) [63-65], and further analyzed with GraphPad Prism 8.3.0 software. To represent expression data in boxplots (box and whiskers, Turkey's method), cell lines were grouped by primary disease (cancer type) and sorted by decreasing mean of gene expression. A horizontal line within each box marks the median value. A "+" within each data group marks the mean value. The $D D R 2$ vs. RET co-expression 
graph (Fig. 4C) was plotted using the original CCLE plotting option with data grouped by cancer type/subtype.

Supplementary Information The online version contains supplementary material available at https://doi.org/10.1007/s10555-021-10001-7.

Author contribution JR was involved in project conceptualization, data curation, formal analysis, investigation, methodology, project administration, resources, supervision, visualization, writing, review, and editing of the original draft. JMS was involved in formal analysis, funding acquisition, investigation, methodology, project administration, resources, supervision, visualization, review, and editing writing of the original draft.

Data availability Not applicable

Code availability Not applicable

\section{Declarations}

Conflict of interest The authors declare no competing interests.

Open Access This article is licensed under a Creative Commons Attribution 4.0 International License, which permits use, sharing, adaptation, distribution and reproduction in any medium or format, as long as you give appropriate credit to the original author(s) and the source, provide a link to the Creative Commons licence, and indicate if changes were made. The images or other third party material in this article are included in the article's Creative Commons licence, unless indicated otherwise in a credit line to the material. If material is not included in the article's Creative Commons licence and your intended use is not permitted by statutory regulation or exceeds the permitted use, you will need to obtain permission directly from the copyright holder. To view a copy of this licence, visit http://creativecommons.org/licenses/by/4.0/.

\section{References}

1. Blume-Jensen, P., \& Hunter, T. (2001). Oncogenic kinase signalling. Nature, 411(6835). https://doi.org/10.1038/35077225

2. Ullrich, A., \& Schlessinger, J. (1990). Signal transduction by receptors with tyrosine kinase activity. Cell. https://doi.org/10. 1016/0092-8674(90)90801-K

3. Schlessinger, J. (2000, October 13). Cell signaling by receptor tyrosine kinases. Cell. Cell Press. https://doi.org/10.1016/S00928674(00)00114-8

4. Lemmon, M. A., \& Schlessinger, J. (2010). Cell signaling by receptor tyrosine kinases. Cell, 141(7), 1117-1134. https://doi. org/10.1016/j.cell.2010.06.011

5. Bousoik, E., \& Montazeri Aliabadi, H. (2018). "Do we know jack” about JAK? A closer look at JAK/STAT signaling pathway. Frontiers in Oncology. https://doi.org/10.3389/fonc.2018.00287

6. Roy, J. P., Halford, M. M., \& Stacker, S. A. (2018). The biochemistry, signalling and disease relevance of RYK and other WNTbinding receptor tyrosine kinases. Growth Factors, 36(1-2), 15-40. https://doi.org/10.1080/08977194.2018.1472089

7. Louis, C. U., \& Shohet, J. M. (2015). Neuroblastoma: Molecular pathogenesis and therapy. Annual Review of Medicine, 66, 49-63. https://doi.org/10.1146/annurev-med-011514-023121
8. Pugh, T. J., Morozova, O., Attiyeh, E. F., Asgharzadeh, S., Wei, J. S., Auclair, D., ... Maris, J. M. (2013). The genetic landscape of high-risk neuroblastoma. Nature Genetics, 45(3). https://doi. org/10.1038/ng.2529

9. Fujita, T., Igarashi, J., Okawa, E. R., Gotoh, T., Manne, J., Kolla, V., ... Brodeur, G. M. (2008). CHD5, a tumor suppressor gene deleted from 1p36.31 in neuroblastomas. Journal of the National Cancer Institute, 100(13). https://doi.org/10.1093/jnci/djn176

10. Theissen, J., Oberthuer, A., Hombach, A., Volland, R., Hertwig, F., Fischer, M., ... Berthold, F. (2014). Chromosome 17/17q gain and unaltered profiles in high resolution array-CGH are prognostically informative in neuroblastoma. Genes Chromosomes and Cancer, 53(8). https://doi.org/10.1002/gcc.22174

11. Mossé, Y. P., Laudenslager, M., Longo, L., Cole, K. A., Wood, A., Attiyeh, E. F., ... Maris, J. M. (2008). Identification of ALK as a major familial neuroblastoma predisposition gene. Nature, 455(7215). https://doi.org/10.1038/nature07261

12. Minuti, G., D'Incecco, A., Landi, L., \& Cappuzzo, F. (2014). Protein kinase inhibitors to treat non-small-cell lung cancer. Expert Opinion on Pharmacotherapy, 15(9). https://doi.org/ 10.1517/14656566.2014.909412

13. ULIVI, P., ZOLI, W., CAPELLI, L., CHIADINI, E., CALISTRI, D., \& AMADORI, D. (2013). Target therapy in NSCLC patients: Relevant clinical agents and tumour molecular characterisation. Molecular and Clinical Oncology, 1(4). https:// doi.org/10.3892/mco. 2013.100

14. Reiff, T., Huber, L., Kramer, M., Delattre, O., Janoueix-Lerosey, I., \& Rohrer, H. (2011). Midkine and Alk signaling in sympathetic neuron proliferation and neuroblastoma predisposition. Development, 138(21). https://doi.org/10.1242/dev. 072157

15. Wang, M., Zhou, C., Sun, Q., Cai, R., Li, Y., Wang, D., \& Gong, L. (2013). ALK amplification and protein expression predict inferior prognosis in neuroblastomas. Experimental and Molecular Pathology, 95(2). https://doi.org/10.1016/j.yexmp.2013.06.002

16. Agarwal, S., Lakoma, A., Chen, Z., Hicks, J., Metelitsa, L. S., Kim, E. S., \& Shohet, J. M. (2015). G-CSF promotes neuroblastoma tumorigenicity and metastasis via STAT3-dependent cancer stem cell activation. Cancer Research, 75(12), 2566-2579. https://doi.org/10.1158/0008-5472.CAN-14-2946

17. Schulte, J. H., Lindner, S., Bohrer, A., Maurer, J., De Preter, K., Lefever, S., ... Schramm, A. (2013). MYCN and ALKF1174L are sufficient to drive neuroblastoma development from neural crest progenitor cells. Oncogene, 32(8). https://doi.org/10.1038/ onc.2012.106

18. Fantauzzo, K. A., \& Soriano, P. (2015). Receptor tyrosine kinase signaling: Regulating neural crest development one phosphate at a time. In Current Topics in Developmental Biology (Vol. 111). https://doi.org/10.1016/bs.ctdb.2014.11.005

19. Koster, J., Molenaar, J. J., \& Versteeg, R. (2015, November 15). Abstract A2-45: R2: Accessible web-based genomics analysis and visualization platform for biomedical researchers. Cancer Research. American Association for Cancer Research. https:// doi.org/10.1158/1538-7445.TRANSCAGEN-A2-45

20. Kung, J. E., \& Jura, N. (2019). Prospects for pharmacological targeting of pseudokinases. Nature Reviews Drug Discovery, 18(7), 501-526. https://doi.org/10.1038/s41573-019-0018-3

21. Brodeur, G. M., Minturn, J. E., Ho, R., Simpson, A. M., Iyer, R., Varela, C. R., ... Evans, A. E. (2009). Trk receptor expression and inhibition in neuroblastomas. Clinical Cancer Research. https://doi.org/10.1158/1078-0432.CCR-08-1815

22. Higashi, M., Sakai, K., Fumino, S., Aoi, S., Furukawa, T., \& Tajiri, T. (2019). The roles played by the MYCN, Trk, and ALK genes in neuroblastoma and neural development. Surgery Today, 49(9), 721-727. https://doi.org/10.1007/s00595-019-01790-0 
23. Tang, X. X., Evans, A. E., Zhao, H., Cnaan, A., London, W., Cohn, S. L., ... Ikegaki, N. (1999). High-level expression of EPHB6, EFNB2, and EFNB3 is associated with low tumor stage and high TrkA expression in human neuroblastomas. Clinical Cancer Research, 5(6), 1491-1496.

24. Tang, X. X., Zhao, H., Robinson, M. E., Cohen, B., Cnaan, A., London, W., ... Ikegaki, N. (2000). Implications of EPHB6, EFNB2, and EFNB3 expressions in human neuroblastoma. Proceedings of the National Academy of Sciences of the United States of America, 97(20). https://doi.org/10.1073/pnas.19012 3297

25. Nozato, M., Kaneko, S., Nakagawara, A., \& Komuro, H. (2013). Epithelial-mesenchymal transition-related gene expression as a new prognostic marker for neuroblastoma. International Journal of Oncology, 42(1), 134-140. https://doi.org/10.3892/ijo.2012. 1684

26. Wilzén, A., Krona, C., Sveinbjörnsson, B., Kristiansson, E., Dalevi, D., Øra, I., ... Abel, F. (2013). ERBB3 is a marker of a ganglioneuroblastoma/ganglioneuroma-like expression profile in neuroblastic tumours. Molecular Cancer, 12(1), 1-15. https:// doi.org/10.1186/1476-4598-12-70

27. Kim, B., Van Golen, C. M., \& Feldman, E. L. (2004). Insulin-like growth factor-I signaling in human neuroblastoma cells. Oncogene, 23(1), 130-141. https://doi.org/10.1038/sj.onc.1206924

28. Van Golen, C. M., Schwab, T. S., Kim, B., Soules, M. E., Oh, S. S., Fung, K., ... Feldman, E. L. (2006). Insulin-like growth factor-I receptor expression regulates neuroblastoma metastasis to bone. Cancer Research, 66(13), 6570-6578. https://doi.org/ 10.1158/0008-5472.CAN-05-1448

29. Pappano, W. N., Jung, P. M., Meulbroek, J. A., Wang, Y. C., Hubbard, R. D., Zhang, Q., ... Wang, J. (2009). Reversal of oncogene transformation and suppression of tumor growth by the novel IGF1R kinase inhibitor A-928605. BMC Cancer, 9, 314. https:// doi.org/10.1186/1471-2407-9-314

30. Wang, X. H., Wu, H. Y., Gao, J., Wang, X. H., Gao, T. H., \& Zhang, S. F. (2019). IGF1R facilitates epithelial-mesenchymal transition and cancer stem cell properties in neuroblastoma via the STAT3/AKT axis. Cancer Management and Research, 11, 5459-5472. https://doi.org/10.2147/CMAR.S196862

31. Kurihara, S., Hakuno, F., \& Takahashi, S. I. (2000). Insulin-like growth factor-I-dependent signal transduction pathways leading to the induction of cell growth and differentiation of human neuroblastoma cell line SH-SY5Y: The roles of MAP kinase pathway and PI 3-kinase pathway. Endocrine Journal, 47(6), 739-751. https://doi.org/10.1507/endocrj.47.739

32. Luberg, K., Park, R., Aleksejeva, E., \& Timmusk, T. (2015). Novel transcripts reveal a complex structure of the human TRKA gene and imply the presence of multiple protein isoforms. $B M C$ Neuroscience, 16(1). https://doi.org/10.1186/s12868-015-0215-x

33. Reinhardt, R. R., Chin, E., Zhang, B., Roth, R. A., \& Bondy, C. A. (1994). Selective coexpression of insulin receptor-related receptor (IRR) and TRK in NGF-sensitive neurons. Journal of Neuroscience, 14(8). https://doi.org/10.1523/jneurosci.14-0804674.1994

34. Weber, A., Huesken, C., Bergmann, E., Kiess, W., Christiansen, N. M., \& Christiansen, H. (2003). Coexpression of insulin receptor-related receptor and insulin-like growth factor 1 receptor correlates with enhanced apoptosis and dedifferentiation in human neuroblastomas. Clinical Cancer Research, 9(15).

35. Fakhari, M., Pullirsch, D., Abraham, D., Paya, K., Hofbauer, R., Holzfeind, P., ... Aharinejad, S. (2002). Selective upregulation of vascular endothelial growth factor receptors neuropilin-1 and -2 in human neuroblastoma. Cancer, 94(1). https://doi.org/10. $1002 / \mathrm{cncr} .10177$

36. Lowery, C. D., Blosser, W., Dowless, M., Renschler, M., Perez, L. V., Stephens, J., ... Falcon, B. (2019). Anti-VEGFR2 therapy delays growth of preclinical pediatric tumor models and enhances anti-tumor activity of chemotherapy. Oncotarget, 10(53), 55235533. https://doi.org/10.18632/oncotarget.27148

37. Becker, J., Pavlakovic, H., Ludewig, F., Wilting, F., Weich, H. A., Albuquerque, R., ... Wilting, J. (2010). Neuroblastoma progression correlates with downregulation of the lymphangiogenesis inhibitor sVEGFR-2. Clinical Cancer Research, 16(5), 1431-1441. https://doi.org/10.1158/1078-0432.CCR-09-1936

38. Weng, W. C., Lin, K. H., Wu, P. Y., Ho, Y. H., Liu, Y. L., Wang, B. J., ... Lee, H. (2017). VEGF expression correlates with neuronal differentiation and predicts a favorable prognosis in patients with neuroblastoma. Scientific Reports, 7(1), 1-11. https://doi. org/10.1038/s41598-017-11637-8

39. Koussounadis, A., Langdon, S. P., Um, I. H., Harrison, D. J., \& Smith, V. A. (2015). Relationship between differentially expressed mRNA and mRNA-protein correlations in a xenograft model system. Scientific Reports 2015 5:1, 5(1), 1-9. https://doi. org/10.1038/srep10775

40. Liu, Y., Beyer, A., \& Aebersold, R. (2016). Leading edge review on the dependency of cellular protein levels on mRNA abundance. https://doi.org/10.1016/j.cell.2016.03.014

41. DeNardo, B. D., Holloway, M. P., Ji, Q., Nguyen, K. T., Cheng, Y., Valentine, M. B., ... Altura, R. A. (2013). Quantitative phosphoproteomic analysis identifies activation of the RET and IGF1R/IR signaling pathways in neuroblastoma. PLoS ONE, 8(12), 1-16. https://doi.org/10.1371/journal.pone.0082513

42. Palacios-Moreno, J., Foltz, L., Guo, A., Stokes, M. P., Kuehn, E. D., George, L., ... Grimes, M. L. (2015). Neuroblastoma tyrosine kinase signaling networks involve FYN and LYN in endosomes and lipid rafts. PLoS Computational Biology, 11(4), 1-33. https://doi.org/10.1371/journal.pcbi.1004130

43. Paratcha, G., \& Ledda, F. (2008). GDNF and GFR $\alpha$ : A versatile molecular complex for developing neurons. Trends in Neurosciences, 31(8). https://doi.org/10.1016/j.tins.2008.05.003

44. Ernsberger, U. (2008). The role of GDNF family ligand signalling in the differentiation of sympathetic and dorsal root ganglion neurons. Cell and Tissue Research. https://doi.org/10.1007/ s00441-008-0634-4

45. Rochette, L., Zeller, M., Cottin, Y., \& Vergely, C. (2020). Insights into mechanisms of GDF15 and receptor GFRAL: Therapeutic targets. https://doi.org/10.1016/j.tem.2020.10.004

46. De Falco, V., Carlomagno, F., Li, H., \& yu, \& Santoro, M. (2017). The molecular basis for RET tyrosine-kinase inhibitors in thyroid cancer. Best Practice and Research: Clinical Endocrinology and Metabolism. https://doi.org/10.1016/j.beem.2017.04. 013

47. Takahashi, M., \& Cooper, G. M. (1987). ret transforming gene encodes a fusion protein homologous to tyrosine kinases. Molecular and Cellular Biology, 7(4). https://doi.org/10.1128/mcb.7. 4.1378

48. Ishizaka, Y., Itoh, F., Tahira, T., Ikeda, I., Ogura, T., Sugimura, T., \& Nagao, M. (1989). Presence of aberrant transcripts of ret proto-oncogene in a human papillary thyroid carcinoma cell line. Japanese Journal of Cancer Research, 80(12). https://doi.org/10. 1111/j.1349-7006.1989.tb01645.x

49. Nagao, M., Ishizaka, Y., Nakagawara, A., Kohno, K., Kuwano, M., Tahira, T., ... Sugimura, T. (1990). Expression of ret protooncogene in human neuroblastomas. Japanese Journal of Cancer Research, 81(4). https://doi.org/10.1111/j.1349-7006.1990.tb025 66. $\mathrm{x}$

50. Iwamoto, T., Taniguchi, M., Wajjwalku, W., Nakashima, I., \& Takahashi, M. (1993). Neuroblastoma in a transgenic mouse carrying a metallothionein/ret fusion gene. British Journal of Cancer, 67(3), 504-507. https://doi.org/10.1038/bjc.1993.94

51. Takada, N., Isogai, E., Kawamoto, T., Nakanishi, H., Todo, S., \& Nakagawara, A. (2001). Retinoic acid-induced apoptosis of 
the CHP134 neuroblastoma cell line is associated with nuclear accumulation of p53 and is rescued by the GDNF/Ret signal. Medical And Pediatric Oncology, 36(1), 122-126. Retrieved from http://search.ebscohost.com/login.aspx ?direct=true $\& \mathrm{db}=$ cmedm\&AN=11464863\&lang=de\&site=ehost-live

52. Ishida, M., Ichihara, M., Mii, S., Jijiwa, M., Asai, N., Enomoto, A., ... Takahashi, M. (2007). Sprouty2 regulates growth and differentiation of human neuroblastoma cells through RET tyrosine kinase. Cancer Science, 98(6), 815-821. https://doi.org/10. 1111/j.1349-7006.2007.00457.x

53. Futami, H., \& Sakai, R. (2009). RET protein promotes nonadherent growth of NB-39-nu neuroblastoma cell line. Cancer Science, 100(6), 1034-1039. https://doi.org/10.1111/j.13497006.2009.01143.x

54. Ding, X., Xiang, L., Wang, N., Zhao, Z., Jin, X., Sun, Y., ... Jin, X. (2014). Vandetanib-induced inhibition of neuroblastoma cell migration and invasion is associated with downregulation of the SDF-1/CXCR4 axis and matrix metalloproteinase 14. Oncology Reports, 31(3), 1165-1174. https://doi.org/10.3892/or.2013.2963

55. Mabruk, Z. A., Ahmed, S. B. M., Thomas, A. C., \& Prigent, S. A. (2018). The role of the ShcD and RET interaction in neuroblastoma survival and migration. Biochemistry and Biophysics Reports, 13(July 2017), 99-108. https://doi.org/10.1016/j.bbrep. 2018.01.007

56. Siaw, J. T., Gabre, J. L., Uçkun, E., Vigny, M., Zhang, W., Van den Eynden, J., ... Guan, J. (2021). Loss of ret promotes mesenchymal identity in neuroblastoma cells. Cancers, 13(8). https:// doi.org/10.3390/cancers13081909

57. Cazes, A., Lopez-Delisle, L., Tsarovina, K., Pierre-Eugène, C., De Preter, K., Peuchmaur, M., ... Janoueix-Lerosey, I. (2014). Activated Alk triggers prolonged neurogenesis and Ret upregulation providing a therapeutic target in ALK-mutated neuroblastoma. Oncotarget, 5(9), 2688-2702. https://doi.org/10.18632/ oncotarget. 1883

58. Lopez-Delisle, L., Pierre-Eugène, C., Louis-Brennetot, C., Surdez, D., Raynal, V., Baulande, S., ... Janoueix-Lerosey, I. (2018). Activated ALK signals through the ERK-ETV5-RET pathway to drive neuroblastoma oncogenesis. Oncogene, 37(11), 1417-1429. https://doi.org/10.1038/s41388-017-0039-5

59. Zhang, L., Scorsone, K., Woodfield, S. E., \& Zage, P. E. (2015). Sensitivity of neuroblastoma to the novel kinase inhibitor cabozantinib is mediated by ERK inhibition. Cancer Chemotherapy and Pharmacology, 76(5), 977-987. https://doi.org/10.1007/ s00280-015-2871-z

60. Flynn, S. M., Lesperance, J., Macias, A., Phanhthilath, N., Paul, M. R., Kim, J. W., ... Zage, P. E. (2019). The multikinase inhibitor RXDX-105 is effective against neuroblastoma in vitro and in vivo. Oncotarget, 10(59), 6323-6333. https://doi.org/10.18632/ oncotarget. 27259

61. Subramonian, D., Phanhthilath, N., Rinehardt, H., Flynn, S., Huo, Y., Zhang, J., ... Zage, P. E. (2020). Regorafenib is effective against neuroblastoma in vitro and in vivo and inhibits the RAS/MAPK, PI3K/Akt/mTOR and Fos/Jun pathways. British Journal of Cancer, 123(4), 568-579. https://doi.org/10.1038/ s41416-020-0905-8

62. Chen, Z., Zhao, Y., Yu, Y., Pang, J. C., Woodfield, S. E., Tao, L., ... Yang, J. (2017). Small molecule inhibitor regorafenib inhibits RET signaling in neuroblastoma cells and effectively suppresses tumor growth in vivo. Oncotarget, 8(61), 104090-104103. https://doi.org/10.18632/oncotarget.22011

63. Barretina, J., Caponigro, G., Stransky, N., Venkatesan, K., Margolin, A. A., Kim, S., ... Garraway, L. A. (2012). The Cancer Cell Line Encyclopedia enables predictive modelling of anticancer drug sensitivity. Nature 2012 483:7391, 483(7391), 603-607. https://doi.org/10.1038/nature11003
64. Ghandi, M., Huang, F. W., Jané-Valbuena, J., Kryukov, G. V., Lo, C. C., McDonald, E. R., ... Sellers, W. R. (2019). Next-generation characterization of the Cancer Cell Line Encyclopedia. Nature 2019 569:7757, 569(7757), 503-508. https://doi.org/10. 1038/s41586-019-1186-3

65. Nusinow, D. P., Szpyt, J., Ghandi, M., Rose, C. M., McDonald, E. R., Kalocsay, M., ... Gygi, S. P. (2020). Quantitative proteomics of the Cancer Cell Line Encyclopedia. Cell, 180(2), 387-402.e16. https://doi.org/10.1016/J.CELL.2019.12.023

66. Bunone, G., Borrello, M. G., Picetti, R., Bongarzone, I., Peverali, F. A., De Franciscis, V., ... Pierotti, M. A. (1995). Induction of RET proto-oncogene expression in neuroblastoma cells precedes neuronal differentiation and is not mediated by protein synthesis. Experimental Cell Research, 217(1). https://doi.org/10.1006/ excr.1995.1067

67. D’Alessio, A., De Vita, G., Cali, G., Nitsch, L., Fusco, A., Vecchio, G., ... De Franciscis, V. (1995). Expression of the RET oncogene induces differentiation of SK-N-BE neuroblastoma cells. Cell Growth and Differentiation, 6(11).

68. Peterson, S., \& Bogenmann, E. (2004). The RET and TRKA pathways collaborate to regulate neuroblastoma differentiation. Oncogene, 23(1), 213-225. https://doi.org/10.1038/sj.onc.12069 80

69. Cerchia, L., D’Alessio, A., Amabile, G., Duconge, F., Pestourie, C., Tavitian, B., ... De Franciscis, V. (2006). An autocrine loop involving ret and glial cell-derived neurotrophic factor mediates retinoic acid-induced neuroblastoma cell differentiation. Molecular Cancer Research, 4(7), 481-488. https://doi.org/10.1158/ 1541-7786.MCR-06-0050

70. Esposito, C. L., D'Alessio, A., de Franciscis, V., \& Cerchia, L. (2008). A cross-talk between TrkB and ret tyrosine kinase receptors mediates neuroblastoma cells differentiation. PLOS ONE, 3(2). https://doi.org/10.1371/journal.pone.0001643

71. Yamada, S., Nomura, T., Uebersax, L., Matsumoto, K., Fujita, S., Miyake, M., \& Miyake, J. (2007). Retinoic acid induces functional c-Ret tyrosine kinase in human neuroblastoma. NeuroReport, 18(4), 359-363. https://doi.org/10.1097/WNR.0b013e3280 $1299 \mathrm{~b} 4$

72. Lambertz, I., Kumps, C., Claeys, S., Lindner, S., Beckers, A., Janssens, E., ... De Preter, K. (2015). Upregulation of MAPK negative feedback regulators and RET in mutant ALK neuroblastoma: Implications for targeted treatment. Clinical Cancer Research, 21(14), 3327-3339. https://doi.org/10.1158/10780432.CCR-14-2024

73. Li, Z., Xie, J., Fei, Y., Gao, P., Xie, Q., Gao, W., \& Xu, Z. (2019). GDNF family receptor alpha 2 promotes neuroblastoma cell proliferation by interacting with PTEN. Biochemical and Biophysical Research Communications, 510(3). https://doi.org/10.1016/j. bbrc.2018.12.169

74. Orentas, R. J., Khan, J., Sindiri, S., Duris, C., Wen, X., He, J., ... Jarzembowski, J. (2017). Paired expression analysis of tumor cell surface antigens. Front. Oncol, 7, 173. https://doi.org/10.3389/ fonc. 2017.00173

75. Tetri, L. H., Kolla, V., Golden, R. L., Iyer, R., Croucher, J. L., Choi, J. H., ... Brodeur, G. M. (2020). RET receptor expression and interaction with TRK receptors in neuroblastomas. Oncology Reports, 44(1), 263-272. https://doi.org/10.3892/or.2020.7583

76. Foltz, L., Palacios-Moreno, J., Mayfield, M., Kinch, S., Dillon, J., Syrenne, J., ... Grimes, M. (2020). PAG1 directs SRC-family kinase intracellular localization to mediate receptor tyrosine kinase-induced differentiation. Molecular Biology of the Cell, 31(20). https://doi.org/10.1091/MBC.E20-02-0135

77. Agarwal, S., Ghosh, R., Chen, Z., Lakoma, A., Gunaratne, P. H., Kim, E. S., \& Shohet, J. M. (2016). Transmembrane adaptor protein PAG1 is a novel tumor suppressor in neuroblastoma. 
Oncotarget, 7(17), 24018. https://doi.org/10.18632/ONCOT ARGET.8116

78. Shrivastava, A., Radziejewski, C., Campbell, E., Kovac, L., McGlynn, M., Ryan, T. E., ... Yancopoulos, G. D. (1997). An orphan receptor tyrosine kinase family whose members serve as nonintegrin collagen receptors. Molecular Cell, 1(1). https://doi. org/10.1016/S1097-2765(00)80004-0

79. Vogel, W., Gish, G. D., Alves, F., \& Pawson, T. (1997). The discoidin domain receptor tyrosine kinases are activated by collagen. Molecular Cell, 1(1). https://doi.org/10.1016/S10972765(00)80003-9

80. Vogel, W. F., Aszódi, A., Alves, F., \& Pawson, T. (2001). Discoidin domain receptor 1 tyrosine kinase has an essential role in mammary gland development. Molecular and Cellular Biology, 21(8). https://doi.org/10.1128/mcb.21.8.2906-2917.2001

81. Olaso, E., Labrador, J. P., Wang, L., Ikeda, K., Eng, F. J., Klein, R., ... Friedman, S. L. (2002). Discoidin domain receptor 2 regulates fibroblast proliferation and migration through the extracellular matrix in association with transcriptional activation of matrix metalloproteinase-2. Journal of Biological Chemistry, 277(5). https://doi.org/10.1074/jbc.M107571200

82. Rammal, H., Saby, C., Magnien, K., Van-Gulick, L., Garnotel, R., Buache, E., ... Morjani, H. (2016). Discoidin domain receptors: Potential actors and targets in cancer. Frontiers in Pharmacology, 7(MAR), 1-13. https://doi.org/10.3389/fphar.2016.00055

83. Henriet, E., Sala, M., Abou Hammoud, A., Tuariihionoa, A., Di Martino, J., Ros, M., \& Saltel, F. (2018). Multitasking discoidin domain receptors are involved in several and specific hallmarks of cancer. Cell Adhesion and Migration, 12(4), 363-377. https:// doi.org/10.1080/19336918.2018.1465156

84. Chander, V. M. H., \& Munshi, A. (2021). Complex roles of discoidin domain receptor tyrosine kinases in cancer. Clinical and Translational Oncology, (0123456789). https://doi.org/10.1007/ s12094-021-02552-6

85. Ford, C. E., Lau, S. K., Zhu, C. Q., Andersson, T., Tsao, M. S., \& Vogel, W. F. (2007). Expression and mutation analysis of the discoidin domain receptors 1 and 2 in non-small cell lung carcinoma. British Journal of Cancer, 96(5). https://doi.org/10.1038/ sj.bjc. 6603614

86. Hammerman, P. S., Sos, M. L., Ramos, A. H., Xu, C., Dutt, A., Zhou, W., ... Meyerson, M. (2011). Mutations in the DDR2 kinase gene identify a novel therapeutic target in squamous cell lung cancer. Cancer Discovery, 1(1). https://doi.org/10.1158/ 2159-8274.CD-11-0005

87. Beauchamp, E. M., Woods, B. A., Dulak, A. M., Tan, L., Xu, C., Gray, N. S., ... Hammerman, P. S. (2014). Acquired resistance to dasatinib in lung cancer cell lines conferred by DDR2 gatekeeper mutation and NF1 loss. Molecular Cancer Therapeutics, 13(2). https://doi.org/10.1158/1535-7163.MCT-13-0817

88. Wang, J., Li, L., Liu, S., Zhao, Y., Wang, L., \& Du, G. (2016). FOXC1 promotes melanoma by activating MST1R/PI3K/AKT pathway and is associated with poor prognosis in melanoma. Oncotarget, 7(51), 84375-84387. https://doi.org/10.18632/oncot arget. 11224

89. Van Groningen, T., Koster, J., Valentijn, L. J., Zwijnenburg, D. A., Akogul, N., Hasselt, N. E., ... Versteeg, R. (2017). Neuroblastoma is composed of two super-enhancer-associated differentiation states. Nature Genetics, 49(8), 1261-1266. https://doi. org/10.1038/ng.3899

90. Bildsoe, H., Fan, X., Wilkie, E. E., Ashoti, A., Jones, V. J., Power, M., ... Loebel, D. A. F. (2016). Transcriptional targets of TWIST1 in the cranial mesoderm regulate cell-matrix interactions and mesenchyme maintenance. Developmental Biology, 418(1), 189-203. https://doi.org/10.1016/j.ydbio.2016.08.016
91. Grither, W. R., Divine, L. M., Meller, E. H., Wilke, D. J., Desai, R. A., Loza, A. J., ... Fuh, K. C. (2018). TWIST1 induces expression of discoidin domain receptor 2 to promote ovarian cancer metastasis. Oncogene, 37(13), 1714-1729. https://doi.org/10. 1038/s41388-017-0043-9

92. Zhu, Q. Q., Ma, C., Wang, Q., Song, Y., \& Lv, T. (2016). The role of TWIST1 in epithelial-mesenchymal transition and cancers. Tumor Biology, 37(1), 185-197. https://doi.org/10.1007/ s13277-015-4450-7

93. Zhang, K., Corsa, C. A., Ponik, S. M., Prior, J. L., PiwnicaWorms, D., Eliceiri, K. W., ... Longmore, G. D. (2013). The collagen receptor discoidin domain receptor 2 stabilizes SNAIL1 to facilitate breast cancer metastasis. Nature Cell Biology, 15(6). https://doi.org/10.1038/ncb2743

94. Selmi, A., de Saint-Jean, M., Jallas, A. C., Garin, E., Hogarty, M. D., Bénard, J., ... Valsesia-Wittmann, S. (2015). TWIST1 is a direct transcriptional target of MYCN and MYC in neuroblastoma. Cancer Letters, 357(1), 412-418. https://doi.org/10.1016/j. canlet.2014.11.056

95. Orr-Urtreger, A., Bedford, M. T., Do, M. S., Eisenbach, L., \& Lonai, P. (1992). Developmental expression of the $\alpha$ receptor for platelet-derived growth factor, which is deleted in the embryonic lethal Patch mutation. Development, 115(1).

96. Olson, L. E., \& Soriano, P. (2009). Increased PDGFR $\alpha$ activation disrupts connective tissue development and drives systemic fibrosis. Developmental Cell, 16(2). https://doi.org/10.1016/j. devcel.2008.12.003

97. Heinrich, M. C., Corless, C. L., Demetri, G. D., Blanke, C. D., Von Mehren, M., Joensuu, H., ... Fletcher, J. A. (2003). Kinase mutations and imatinib response in patients with metastatic gastrointestinal stromal tumor. Journal of Clinical Oncology, 21(23). https://doi.org/10.1200/JCO.2003.04.190

98. Heldin, C. H., Lennartsson, J., \& Westermark, B. (2018). Involvement of platelet-derived growth factor ligands and receptors in tumorigenesis. Journal of Internal Medicine, 283(1), 16-44. https://doi.org/10.1111/joim.12690

99. Zanelli, M., Smith, M., Zizzo, M., Carloni, A., Valli, R., De Marco, L., ... Ascani, S. (2019). A tricky and rare cause of pulmonary eosinophilia: Myeloid/lymphoid neoplasm with eosinophilia and rearrangement of PDGFRA. BMC Pulmonary Medicine, 19(1). https://doi.org/10.1186/s12890-019-0967-7

100. Smith, J. S., Wang, X. Y., Qian, J., Hosek, S. M., Scheithauer, B. W., Jenkins, R. B., \& James, C. D. (2000). Amplification of the platelet-derived growth factor receptor-a (PDGFRA) gene occurs in oligodendrogliomas with grade IV anaplastic features. Journal of Neuropathology and Experimental Neurology, 59(6), 495-503. https://doi.org/10.1093/jnen/59.6.495

101. Arai, H., Ueno, T., Tangoku, A., Yoshino, S., Abe, T., Kawauchi, S., ... Sasaki, K. (2003). Detection of amplified oncogenes by genome DNA microarrays in human primary esophageal squamous cell carcinoma: Comparison with conventional comparative genomic hybridization analysis. Cancer Genetics and Cytogenetics, 146(1), 16-21. https://doi.org/10.1016/S01654608(03)00106-7

102. Zhao, J., Roth, J., Bode-Lesniewska, B., Pfaltz, M., Heitz, P. U., \& Komminoth, P. (2002). Combined comparative genomic hybridization and genomic microarray for detection of gene amplifications in pulmonary artery intimal sarcomas and adrenocortical tumors. Genes Chromosomes and Cancer, 34(1), 48-57. https://doi.org/10.1002/gcc.10035

103. Matsui, T., Sano, K., Tsukamoto, T., Ito, M., Takaishi, T., Nakata, H., ... Chihara, K. (1993). Human neuroblastoma cells express $\alpha$ and $\beta$ platelet-derived growth factor receptors coupling with neurotrophic and chemotactic signaling. Journal of Clinical 
Investigation, 92(3), 1153-1160. https://doi.org/10.1172/JCI1 1 6684

104. Beppu, K., Jaboine, J., Merchant, M. S., Mackall, C. L., \& Thiele, C. J. (2004). Effect of imatinib mesylate on neuroblastoma tumorigenesis and vascular endothelial growth factor expression. Journal of the National Cancer Institute, 96(1), 46-55. https:// doi.org/10.1093/jnci/djh004

105. Mei, Y., Wang, Z., Zhang, L., Zhang, Y., Li, X., Liu, H., ... You, H. (2012). Regulation of neuroblastoma differentiation by forkhead transcription factors FOXO1/3/4 through the receptor tyrosine kinase PDGFRA. Proceedings of the National Academy of Sciences of the United States of America, 109(13), 4898-4903. https://doi.org/10.1073/pnas.1119535109

106. Hutt, K. J., McLaughlin, E. A., \& Holland, M. K. (2006). KIT/ KIT ligand in mammalian oogenesis and folliculogenesis: Roles in rabbit and murine ovarian follicle activation and oocyte growth. Biology of Reproduction, 75(3), 421-433. https://doi. org/10.1095/biolreprod.106.051516

107. Luo, R., Gao, J., Wehrle-Haller, B., \& Henion, P. D. (2003). Molecular identification of distinct neurogenic and melanogenic neural crest sublineages. Development, 130(2), 321-330. https://doi.org/10.1242/dev.00213

108. Babaei, M. A., Kamalidehghan, B., Saleem, M., Huri, H. Z., \& Ahmadipour, F. (2016). Receptor tyrosine kinase (c-Kit) inhibitors: A potential therapeutic target in cancer cells. Drug Design, Development and Therapy, 10, 2443-2459. https://doi. org/10.2147/DDDT.S89114

109. Korja, M., Finne, J., Salmi, T. T., Haapasalo, H., Tanner, M., \& Isola, J. (2005). No GIST-type c-kit gain of function mutations in neuroblastic tumours. Journal of Clinical Pathology, 58(7), 762-765. https://doi.org/10.1136/jcp.2004.024331

110. Cohen, P. S., Chan, J. P., Lipkunskaya, M., Biedler, J. L., \& Seeger, R. C. (1994). Expression of stem cell factor and c-kit in human neuroblastoma. Blood, 84(10), 3465-3472. https:// doi.org/10.1182/blood.v84.10.3465.3465

111. Beck, D., Gross, N., Brognara, C., \& Perruisseau, G. (1995). Expression of stem cell factor and its receptor by human neuroblastoma cells and tumors. Blood, 86(8). https://doi.org/10. 1182/blood.v86.8.3132.bloodjournal8683132

112. Smithey, B. E., Pappo, A. S., \& Hill, D. A. (2002). c-kit expression in pediatric solid tumors: A comparative immunohistochemical study. American Journal of Surgical Pathology, 26(4). https://doi.org/10.1097/00000478-200204000-00011

113. Jögi, A., Øra, I., Nilsson, H., Lindeheim, Å., Makino, Y., Poellinger, L., ... Påhlman, S. (2002). Hypoxia alters gene expression in human neuroblastoma cells toward an immature and neural crest-like phenotype. Proceedings of the National Academy of Sciences of the United States of America, 99(10), 7021-7026. https://doi.org/10.1073/pnas.102660199

114. Vitali, R., Cesi, V., Nicotra, M. R., McDowell, H. P., Donfrancesco, A., Mannarino, O., ... Dominici, C. (2003). c-Kit is preferentially expressed in MYCN-amplified neuroblastoma and its effect on cell proliferation is inhibited in vitro by STI571. International Journal of Cancer, 106(2), 147-152. https:// doi.org/10.1002/ijc.11187

115. Uccini, S., Mannarino, O., McDowell, H. P., Pauser, U., Vitali, R., Natali, P. G., ... Dominici, C. (2005). Clinical and molecular evidence for c-kit receptor as a therapeutic target in neuroblastic tumors. Clinical Cancer Research, 11(1), 380-389.

116. Hirschmann-Jax, C., Foster, A. E., Wulf, G. G., Nuchtern, J. G., Jax, T. W., Gobel, U., ... Brenner, M. K. (2004). A distinct "side population" of cells with high drug efflux capacity in human tumor cells. Proceedings of the National Academy of Sciences of the United States of America, 101(39), 1422814233. https://doi.org/10.1073/pnas.0400067101
117. Lau, S. T., Hansford, L. M., Chan, W. K., Chan, G. C. F., Wan, T. S. K., Wong, K. K. Y., ... Ngan, E. S. W. (2015). Prokineticin signaling is required for the maintenance of a de novo population of c-KIT+ cells to sustain neuroblastoma progression. Oncogene, 34(8), 1019-1034. https://doi.org/10.1038/ onc. 2014.24

118. Krams, M., Parwaresch, R., Sipos, B., Heidorn, K., Harms, D., \& Rudolph, P. (2004). Expression of the c-kit receptor characterizes a subset of neuroblastomas with favorable prognosis. Oncogene, 23(2), 588-595. https://doi.org/10.1038/sj.onc. 1207145

119. Shimada, A., Hirato, J., Kuroiwa, M., Kikuchi, A., Hanada, R., Wakai, K., \& Hayashi, Y. (2008). Expression of KIT and PDGFR is associated with a good prognosis in neuroblastoma. Pediatric Blood and Cancer, 50(2). https://doi.org/10.1002/pbc.21288

120. Janoueix-Lerosey, I., Lequin, D., Brugières, L., Ribeiro, A., De Pontual, L., Combaret, V., ... Delattre, O. (2008). Somatic and germline activating mutations of the ALK kinase receptor in neuroblastoma. Nature, 455(7215). https://doi.org/10.1038/natur $\mathrm{e} 07398$

121. Chen, Y., Takita, J., Choi, Y. L., Kato, M., Ohira, M., Sanada, M., ... Ogawa, S. (2008). Oncogenic mutations of ALK kinase in neuroblastoma. Nature, 455(7215). https://doi.org/10.1038/natur e07399

122. Carén, H., Abel, F., Kogner, P., \& Martinsson, T. (2008). High incidence of DNA mutations and gene amplifications of the ALK gene in advanced sporadic neuroblastoma tumours. Biochemical Journal, 416(2). https://doi.org/10.1042/BJ20081834

123. Trigg, R. M., \& Turner, S. D. (2018). ALK in neuroblastoma: Biological and therapeutic implications. Cancers, 10(4). https:// doi.org/10.3390/cancers 10040113

124. Janoueix-Lerosey, I., Lopez-Delisle, L., Delattre, O., \& Rohrer, H. (2018). The ALK receptor in sympathetic neuron development and neuroblastoma. Cell and Tissue Research, 372(2), 325-337. https://doi.org/10.1007/s00441-017-2784-8

125. Umapathy, G., Mendoza-Garcia, P., Hallberg, B., \& Palmer, R. H. (2019). Targeting anaplastic lymphoma kinase in neuroblastoma. APMIS, 127(5), 288-302. https://doi.org/10.1111/apm.12940

126. Yoshikawa, S., McKinnon, R. D., Kokel, M., \& Thomas, J. B. (2003). Wnt-mediated axon guidance via the Drosophila derailed receptor. Nature, 422(6932). https://doi.org/10.1038/nature01522

127. Peradziryi, H., Kaplan, N. A., Podleschny, M., Liu, X., Wehner, P., Borchers, A., \& Tolwinski, N. S. (2011). PTK7/Otk interacts with Wnts and inhibits canonical Wnt signalling. EMBO Journal, 30(18). https://doi.org/10.1038/emboj.2011.236

128. Jing, L., Lefebvre, J. L., Gordon, L. R., \& Granato, M. (2009). Wnt signals organize synaptic prepattern and axon guidance through the zebrafish unplugged/MuSK receptor. Neuron, 61(5). https://doi.org/10.1016/j.neuron.2008.12.025

129. Oishi, I., Suzuki, H., Onishi, N., Takada, R., Kani, S., Ohkawara, B., ... Minami, Y. (2003). The receptor tyrosine kinase Ror2 is involved in non-canonical Wnt5a/JNK signalling pathway. Genes to Cells, 8(7). https://doi.org/10.1046/j.1365-2443.2003.00662.x

130. Green, J., Nusse, R., \& van Amerongen, R. (2014). The role of Ryk and Ror receptor tyrosine kinases in wnt signal transduction. Cold Spring Harbor Perspectives in Biology, 6(2), 1-12. https:// doi.org/10.1101/cshperspect.a009175

131. Debebe, Z., \& Rathmell, W. K. (2015). Ror2 as a therapeutic target in cancer. Pharmacology and Therapeutics, 150, 143-148. https://doi.org/10.1016/j.pharmthera.2015.01.010

132. Oconnell, M. P., Fiori, J. L., Xu, M., Carter, A. D., Frank, B. P., Camilli, T. C., ... Weeraratna, A. T. (2010). The orphan tyrosine kinase receptor, ROR2, mediates Wnt5A signaling in metastatic melanoma. Oncogene, 29(1). https://doi.org/10.1038/onc.2009. 305

133. Rasmussen, N. R., Debebe, Z., Wright, T. M., Brooks, S. A., Sendor, A. B., Brannon, A. R., ... Rathmell, W. K. (2014). 
Expression of Ror2 mediates invasive phenotypes in renal cell carcinoma. PLoS ONE, 9(12). https://doi.org/10.1371/journal. pone. 0116101

134. Xu, Y., Ma, Y. H., Pang, Y. X., Zhao, Z., Lu, J. J., Mao, H. L., \& Liu, P. S. (2017). Ectopic repression of receptor tyrosine kinase-like orphan receptor 2 inhibits malignant transformation of ovarian cancer cells by reversing epithelial-mesenchymal transition. Tumor Biology, 39(5). https://doi.org/10.1177/10104 28317701627

135. Roarty, K., Pfefferle, A. D., Creighton, C. J., Perou, C. M., \& Rosen, J. M. (2017). Ror2-mediated alternative Wnt signaling regulates cell fate and adhesion during mammary tumor progression. Oncogene, 36(43). https://doi.org/10.1038/onc.2017.206

136. Fu, Y., Chen, Y., Huang, J., Cai, Z., \& Wang, Y. (2020). RYK, a receptor of noncanonical Wnt ligand Wnt5a, is positively correlated with gastric cancer tumorigenesis and potential of liver metastasis. American Journal of Physiology - Gastrointestinal and Liver Physiology, 318(2), G352-G360. https://doi.org/10. 1152/AJPGI.00228.2019

137. Katso, R. M. T., Manek, S., Biddolph, S., Whittaker, R., Charnock, M. F. L., Wells, M., \& Ganesan, T. S. (1999). Overexpression of H-Ryk in mouse fibroblasts confers transforming ability in vitro and in vivo: Correlation with up-regulation in epithelial ovarian cancer. Cancer Research, 59(10).

138. Ji, Y., Hao, H., Reynolds, K., Mcmahon, M., \& Zhou, C. J. (2019). cells Wnt signaling in neural crest ontogenesis and oncogenesis. https://doi.org/10.3390/cells8101173

139. Becker, J., \& Wilting, J. (2019). Wnt signaling in neuroblastoma. Cancers, 11(7). https://doi.org/10.3390/cancers11071013

140. Becker, J., \& Wilting, J. (2018). WNT signaling, the development of the sympathoadrenal-paraganglionic system and neuroblastoma. Cellular and Molecular Life Sciences, 75(6), 1057-1070. https://doi.org/10.1007/s00018-017-2685-8

141. Masiakowski, P., \& Carroll, R. D. (1992). A novel family of cell surface receptors with tyrosine kinase-like domain. Journal of Biological Chemistry, 267(36). https://doi.org/10.1016/s00219258(18)35733-8

142. Podleschny, M., Grund, A., Berger, H., Rollwitz, E., \& Borchers, A. (2015). A PTK7/Ror2 co-receptor complex affects xenopus neural crest migration. PLOS ONE, 10(12), 1-19. https://doi.org/ 10.1371/journal.pone.0145169

143. Dave, H., Butcher, D., Anver, M., \& Bollard, C. M. (2019). ROR1 and ROR2-Novel targets for neuroblastoma. Pediatric Hematology and Oncology, 36(6). https://doi.org/10.1080/08880 018.2019.1646365

144. Hernandez Tejada, F. N., Najjar, A., Guerrero, A. D., Flores, L. G., \& Singh, H. (2018). ROR1-specific CAR for neuroblastoma using sleeping beauty -modified t cells. . Journal of Clinical Oncology, 36(15_suppl). https://doi.org/10.1200/jco.2018.36. 15_suppl.10523

145. Illendula, A., Fultang, N., \& Peethambaran, B. (2020). Retinoic acid induces differentiation in neuroblastoma via ROR 1 by modulating retinoic acid response elements. Oncology Reports, 44(3), 1013-1024. https://doi.org/10.3892/or.2020.7681

146. Malik, R., Mambetsariev, I., Fricke, J., Chawla, N., Nam, A., Pharaon, R., \& Salgia, R. (2020). MET receptor in oncology: From biomarker to therapeutic target. In Advances in Cancer Research (Vol. 147). https://doi.org/10.1016/bs.acr.2020.04.006

147. Ichimura, E., Maeshima, A., Nakajima, T., \& Nakamura, T. (1996). Expression of c-met/HGF receptor in human non-small cell lung carcinomas in vitro and in vivo and its prognostic significance. Japanese Journal of Cancer Research, 87(10). https:// doi.org/10.1111/j.1349-7006.1996.tb03111.x

148. Lee, J., Ou, S. H. I., Lee, J. M., Kim, H. C., Hong, M., Kim, S. Y., ... Kim, K. M. (2015). Gastrointestinal malignancies harbor actionable MET exon 14 deletions. Oncotarget, 6(29). https:// doi.org/10.18632/oncotarget.4721

149. Goyal, L., Muzumdar, M. D., \& Zhu, A. X. (2013). Targeting the HGF/c-MET pathway in hepatocellular carcinoma. Clinical Cancer Research. https://doi.org/10.1158/1078-0432.CCR-12-2791

150. Takayama, H., LaRochelle, W. J., Anver, M., Bockman, D. E., \& Merlino, G. (1996). Scatter factor/hepatocyte growth factor as a regulator of skeletal muscle and neural crest development. Proceedings of the National Academy of Sciences of the United States of America, 93(12), 5866-5871. https://doi.org/10.1073/ pnas.93.12.5866

151. Hecht, M., Papoutsi, M., Tran, H. D., Wilting, J., \& Schweigerer, L. (2004). Hepatocyte growth factor/c-Met signaling promotes the progression of experimental human neuroblastomas. Cancer Research, 64(17), 6109-6118. https://doi.org/10.1158/00085472.CAN-04-1014

152. Hecht, M., Schulte, J. H., Eggert, A., Wilting, J., \& Schweigerer, L. (2005). The neurotrophin receptor TrkB cooperates with c-Met in enhancing neuroblastoma invasiveness. Carcinogenesis, 26(12), 2105-2115. https://doi.org/10.1093/carcin/bgi192

153. Schweigerer, L., Rave-Fränk, M., Schmidberger, H., \& Hecht, M. (2005). Sublethal irradiation promotes invasiveness of neuroblastoma cells. Biochemical and Biophysical Research Communications, 330(3), 982-988. https://doi.org/10.1016/j.bbrc.2005.03. 068

154. Yan, B., Lim, M., Zhou, L., Kuick, C. H., Leong, M. Y., Yong, K. J., ... Chang, K. T. E. (2013). Identification of MET genomic amplification, protein expression and alternative splice isoforms in neuroblastomas. Journal of Clinical Pathology, 66(11), 985991. https://doi.org/10.1136/jclinpath-2012-201375

155. Crosswell, H. E., Dasgupta, A., Alvarado, C. S., Watt, T., Christensen, J. G., De, P., ... Findley, H. W. (2009). PHA665752, a small-molecule inhibitor of c-Met, inhibits hepatocyte growth factor-stimulated migration and proliferation of c-Met-positive neuroblastoma cells. BMC Cancer, 9, 1-10. https://doi.org/10. 1186/1471-2407-9-411

156. Scorsone, K., Zhang, L., Woodfield, S. E., Hicks, J., \& Zage, P. E. (2014). The novel kinase inhibitor EMD1214063 is effective against neuroblastoma. Investigational New Drugs, 32(5), 815-824. https://doi.org/10.1007/s10637-014-0107-4

157. Jahangiri, A., De Lay, M., Miller, L. M., Shawn Carbonell, W., Hu, Y. L., Lu, K., ... Aghi, M. K. (2013). Gene expression profile identifies tyrosine kinase c-Met as a targetable mediator of antiangiogenic therapy resistance. Clinical Cancer Research, 19(7), 1773-1783. https://doi.org/10.1158/1078-0432. CCR-12-1281

158. Daudigeos-Dubus, E., Le Dret, L., Bawa, O., Opolon, P., Vievard, A., Villa, I., ... Geoerger, B. (2017). Dual inhibition using cabozantinib overcomes HGF/MET signaling mediated resistance to pan-VEGFR inhibition in orthotopic and metastatic neuroblastoma tumors. International Journal of Oncology, 50(1), 203-211. https://doi.org/10.3892/ijo.2016.3792

159. Ishiwata, T. (2018). Role of fibroblast growth factor receptor-2 splicing in normal and cancer cells. Frontiers in Bioscience Landmark, 23(4). https://doi.org/10.2741/4609

160. Ornitz, D. M., Xu, J., Colvin, J. S., McEwen, D. G., MacArthur, C. A., Coulier, F., ... Goldfarb, M. (1996). Receptor specificity of the fibroblast growth factor family. Journal of Biological Chemistry, 271(25). https://doi.org/10.1074/jbc.271.25.15292

161. Zhang, X., Ibrahimi, O. A., Olsen, S. K., Umemori, H., Mohammadi, M., \& Ornitz, D. M. (2006). Receptor specificity of the fibroblast growth factor family: The complete mammalian FGF family. Journal of Biological Chemistry, 281(23). https://doi.org/ 10.1074/jbc.M601252200

162. De Moerlooze, L., Spencer-Dene, B., Revest, J. M., Hajihosseini, M., Rosewell, I., \& Dickson, C. (2000). An important role for the 
IIIb isoform of fibroblast growth factor receptor 2 (FGFR2) in mesenchymal-epithelial signalling during mouse organogenesis. Development, 127(3). https://doi.org/10.1042/cs099005p

163. Revest, J. M., Spencer-Dene, B., Kerr, K., De Moerlooze, L., Rosewell, I., \& Dickson, C. (2001). Fibroblast growth factor receptor 2-IIIb acts upstream of Shh and Fgf4 and is required for limb bud maintenance but not for the induction of Fgf8, Fgf10, Msx1, or Bmp4. Developmental Biology, 231(1). https://doi.org/ 10.1006/dbio.2000.0144

164. Hierro, C., Alsina, M., Sánchez, M., Serra, V., Rodon, J., \& Tabernero, J. (2017). Targeting the fibroblast growth factor receptor 2 in gastric cancer: Promise or pitfall? Annals of Oncology. https://doi.org/10.1093/annonc/mdx081

165. Li, L., Zhang, S., Wei, L., Wang, Z., Ma, W., Liu, F., \& Qian, Y. (2018). FGF2 and FGFR2 in patients with idiopathic pulmonary fibrosis and lung cancer. Oncology Letters, 16(2). https://doi.org/ 10.3892/ol.2018.8903

166. Fernández-Nogueira, P., Mancino, M., Fuster, G., López-Plana, A., Jauregui, P., Almendro, V., ... Bragado, P. (2020). Tumorassociated fibroblasts promote HER2-targeted therapy resistance through FGFR2 activation. Clinical Cancer Research, 26(6). https://doi.org/10.1158/1078-0432.CCR-19-0353

167. Tyulyandina, A., Harrison, D., Yin, W., Stepanova, E., Kochenkov, D., Solomko, E., ... Tsimafeyeu, I. (2017). Alofanib, an allosteric FGFR2 inhibitor, has potent effects on ovarian cancer growth in preclinical studies. Investigational New Drugs, 35(2). https://doi.org/10.1007/s10637-016-0404-1

168. Stehbens, S. J., Ju, R. J., Adams, M. N., Perry, S. R., Haass, N. K., Bryant, D. M., \& Pollock, P. M. (2018). FGFR2-activating mutations disrupt cell polarity to potentiate migration and invasion in endometrial cancer cell models. Journal of Cell Science, 131(15). https://doi.org/10.1242/jcs.213678

169. Mahipal, A., Tella, S. H., Kommalapati, A., Anaya, D., \& Kim, R. (2019). FGFR2 genomic aberrations: Achilles heel in the management of advanced cholangiocarcinoma. Cancer Treatment Reviews. https://doi.org/10.1016/j.ctrv.2019.06.003

170. Fults, D., Pedone, C. A., Thompson, G. E., Uchiyama, C. M., Gumpper, K. L., Iliev, D., ... Perry, W. L. (1998). Microsatellite deletion mapping on chromosome $10 \mathrm{q}$ and mutation analysis of MMAC1, FAS, and MXI1 in human glioblastoma multiforme. International Journal of Oncology, 12(4). https://doi.org/10. 3892/ijo.12.4.905

171. Healy, E., Belgaid, C., Takata, M., Harrison, D., Zhu, N. W., Burd, D. A. R., ... Rees, J. L. (1998). Prognostic significance of allelic losses in primary melanoma. Oncogene, 16(17). https:// doi.org/10.1038/sj.onc.1200203
172. Trybus, T. M., Burgess, A. C., Wojno, K. J., Glover, T. W., \& Macoska, J. A. (1996). Distinct areas of allelic loss on chromosomal regions $10 \mathrm{p}$ and $10 \mathrm{q}$ in human prostate cancer. Cancer Research, 56(10).

173. Altura, R. A., Maris, J. H., Li, H., Boyett, J. M., Brodeur, G. M., \& Look, A. T. (1997). Novel regions of chromosomal loss in familial neuroblastoma by comparative genomic hybridization. Genes Chromosomes and Cancer, 19(3), 176-184. https:// doi.org/10.1002/(SICI)1098-2264(199707)19:3\%3c176::AIDGCC7\%3e3.0.CO;2-V

174. Lázcoz, P., Muñoz, J., Nistal, M., Pestaña, Á., Encío, I. J., \& Castresana, J. S. (2007). Loss of heterozygosity and microsatellite instability on chromosome arm 10q in neuroblastoma. Cancer Genetics and Cytogenetics, 174(1), 1-8. https://doi.org/10. 1016/j.cancergencyto.2006.08.014

175. Salm, F., Cwiek, P., Ghosal, A., Lucia Buccarello, A., Largey, F., Wotzkow, C., ... Arcaro, A. (2013). RNA interference screening identifies a novel role for autocrine fibroblast growth factor signaling in neuroblastoma chemoresistance. Oncogene, 32(34), 3944-3953. https://doi.org/10.1038/onc.2012.416

176. Emdal, K. B., Pedersen, A. K., Bekker-Jensen, D. B., Lundby, A., Claeys, S., De Preter, K., ... Olsen, J. V. (2018). Integrated proximal proteomics reveals IRS2 as a determinant of cell survival in ALK-driven neuroblastoma. Science Signaling, 11(557). https://doi.org/10.1126/SCISIGNAL.AAP9752/FORMAT/PDF/ OEBPS/PAGES/1.PAGE.XHTML

177. Van Den Eynden, J., Umapathy, G., Ashouri, A., CervantesMadrid, D., Szydzik, J., Ruuth, K., ... Hallberg, B. (2018). Phosphoproteome and gene expression profiling of ALK inhibition in neuroblastoma cell lines reveals conserved oncogenic pathways. Science Signaling, 11(557). https://doi.org/10.1126/ SCISIGNAL.AAR5680

178. Braekeveldt, N., Von Stedingk, K., Fransson, S., MartinezMonleon, A., Lindgren, D., Axelson, H., ... Bexell, D. (2018). Patient-derived xenograft models reveal intratumor heterogeneity and temporal stability in neuroblastoma. Cancer Research, 78(20). https://doi.org/10.1158/0008-5472.CAN-18-0527

Publisher's note Springer Nature remains neutral with regard to jurisdictional claims in published maps and institutional affiliations. 